\title{
The immunoglobulin $\mu$ enhancer core establishes local factor access in nuclear chromatin independent of transcriptional stimulation
}

\author{
Thomas Jenuwein, William C. Forrester, Rong-Guo Qiu, and Rudolf Grosschedl \\ Howard Hughes Medical Institute and Departments of Microbiology and Biochemistry, University of California, San \\ Francisco, California 94143-0414 USA
}

Factor access in chromatin has been proposed to be facilitated by transcriptional enhancers. With the aim of uncoupling factor access from transcriptional stimulation by protein-protein contacts, we analyzed the potential of enhancer fragments to confer accessibility upon a linked promoter for prokaryotic T7 RNA polymerase. Access to the $\mathrm{T} 7$ promoter in pre-B cells from transgenic mice was examined by transcribing chromatin of isolated nuclei with T7 RNA polymerase. A 95-bp immunoglobulin $\mu$ enhancer core element was necessary and sufficient to confer accessibility upon the $T 7$ promoter independent of its chromosomal position. This enhancer-dependent factor access could be uncoupled from an active transcriptional state of the transgene and was not accompanied by the formation of pronounced DNase I hypersensitive sites. Additional $\mu$ enhancer sequences comprising previously identified matrix attachment regions and a cryptic promoter were required to induce DNase I hypersensitivity. Together, these data provide evidence that the 95-bp $\mu$ enhancer core can establish localized factor access in nuclear chromatin independent of detectable transcription by endogenous polymerases and suggest that multiple steps are involved in the alteration of chromatin structure.

[Key Words: Immunoglobulin $\mu$ enhancer; chromatin; locus control; transcription; T7 RNA polymerase]

Received May 12, 1993; revised version accepted August 9, 1993.

The organization of eukaryotic DNA in chromatin limits the accessibility of regulatory sequences for the interaction with nuclear proteins (for review, see Kornberg and Lorch 1991; Felsenfeld 1992; Travers 1992). Biochemical studies involving the removal of histones or the reconstitution of nucleosomal templates demonstrated that the association of histones with DNA impaired the interaction with RNA polymerases (Williamson and Felsenfeld 1978) and sequence-specific interaction with transcription factors (Workman et al. 1988; Laybourn and Kadonaga 1991; Taylor et al. 1991). This limitation of factor access to regulatory sequences was further corroborated by genetic evidence in yeast, indicating that alterations in the stoichiometry (Clark-Adams et al. 1988; Han and Grunstein 1988) or structure (Durrin et al. 1991) of core histones are accompanied by the aberrant transcriptional activation of several genes. The binding of nuclear nonhistone proteins to transcriptional control regions is reflected by alterations in the chromatin structure that can be detected as DNase I hypersensitive sites (HS sites) (for review, see Elgin 1988; Gross and Garrard 1988). The presence of HS sites usually correlates with an active transcriptional state of the associated gene (Weintraub and Groudine 1976; Wu et al.
1979; for review, see Weintraub 1985). Some HS sites, however, can be detected in committed cell types that do not yet express the associated gene (Forrester et al. 1987; Blom van Assendelft et al. 1989; Ford et al. 1992), raising the possibility that structural alterations in nuclear chromatin precede the onset of transcription. Many, but not all, HS sites colocalize with transcriptional enhancers at their normal chromosomal locations (for review, see Gross and Garrard 1988), and at ectopic integration sites (Pikaart et al. 1992).

Transcriptional stimulation by enhancers in vivo has been attributed to the interaction of enhancer-bound factors with components of the basal transcription machinery (for review, see Serfling et al. 1985; Ptashne 1986; Maniatis et al. 1987). Stimulation of transcription of naked DNA templates by enhancers in vitro, however, is minimal (Serfling et al. 1985; Ptashne 1986), suggesting that one component of enhancer function could be to alter the accessibility of target sites in chromatin. Such a putative role is consistent with the ability of many enhancers to establish transcriptional activity in germ-line transformation assays. Although the function of enhancers is influenced by the site of integration (for review, see Wilson et al. 1990), another set of genetic control ele- 
ments, termed locus control regions (LCRs), has been shown to govern correct developmental regulation of gene expression independent of chromosomal position (Grosveld et al. 1987; Greaves et al. 1989). LCRs represent complex regulatory elements that contain sequences displaying enhancer function (for review, see Townes and Behringer 1990). Some LCRs also include matrix-attachment regions (MARs), which mediate association of DNA with the nuclear matrix in vitro /Gasser and Laemmli 1986; Cockerill et al. 1987; Jarman and Higgs 1988). MAR sequences have been shown recently to impart position independence on transcriptional enhancers (Stief et al. 1989; McKnight et al. 1992).

Studies aimed at gaining insight into the mechanisms regulating factor access in chromatin examined the interaction of purified transcription factors with in vitroassembled nucleosomal templates. These studies indicated that factors of the general transcription machinery required binding to DNA before the assembly of a nucleosomal template (Workman et al. 1988; Knezetic et al. 1988). In contrast, some, but not all, transcriptional activators examined were found to facilitate transcription of nucleosomal templates in vitro (Workman et al. 1988; Laybourn and Kadonaga 1991) and to be competent for binding to preassembled nucleosomal DNA in vitro (Taylor et al. 1991). In particular, the GAL4 DNA-binding domain can interact with its binding site in a nucleosome to form a ternary complex. This complex is metastable and dissociates either into a stable binary GAL4 DNA complex lacking histones or into a reformed nucleosome lacking GAL4 (Workman and Kingston 1992). Together, these experiments suggest that transcriptional activators alone can gain access to nucleosomal DNA in vitro.

In vivo genomic footprinting of enhancers indicated that factor binding sites are occupied only in cell types in which the enhancers are functional (Ephrussi et al. 1985; Becker et al. 1987). In nonexpressing cells, even binding sites for ubiquitous factors are not occupied (Becker et al. 1987). This suggests that nuclear chromatin in vivo may be less permissive for factor access than nucleosomal DNA in vitro and that factor binding in vivo may depend on cooperative interactions between multiple DNAbinding factors. Thus, enhancers, comprising multiple and clustered binding sites for transcription factors are candidates for elements initiating factor access in nuclear chromatin in vivo.

\section{Results}

\section{Experimental strategy}

Studies addressing the putative role of enhancers in regulating factor access in chromatin have been complicated by the functional interaction of enhancers with promoters for RNA polymerase II. The possibility of protein-protein interactions between enhancer-bound factors and components of the basal transcription machinery makes it difficult to distinguish the contribution of two principal mechanisms underlying stimulation of promoter activity: factor access in chromatin versus protein-protein contacts (discussed in Chen et al. 1987). Moreover, the cause-and-effect relationship between changes in the chromatin structure and transcription is still largely unclear because of the difficulty in uncoupling the events that initiate accessibility from those of transcriptional activity itself.

We designed experiments that allow the analysis of enhancer function without the complication of interaction with promoter-bound proteins and in the absence of transcription by RNA polymerase II (Fig. 1). We adopted

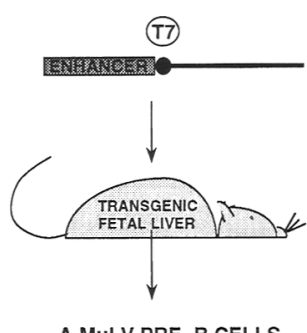

A-MULV PRE -B CELLS
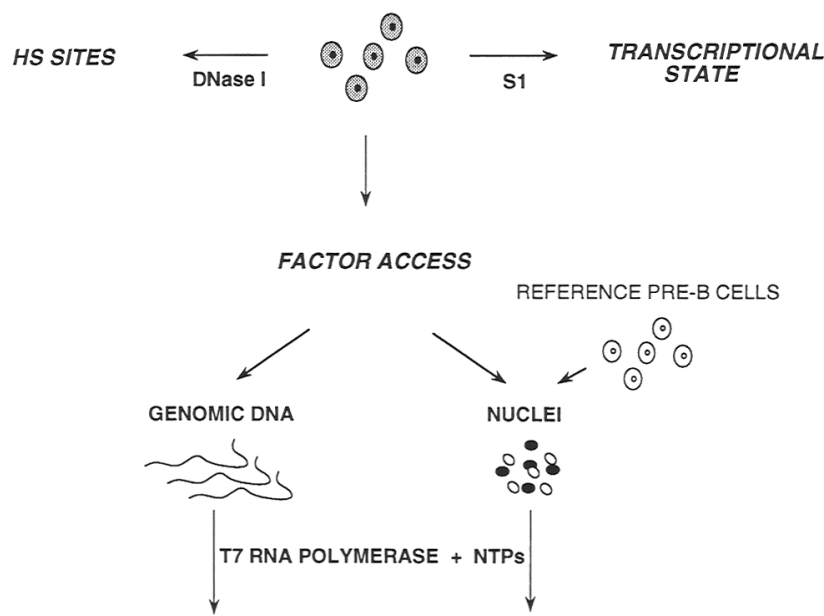

RNA ANALYSIS OF T7-GENERATED TRANSCRIPTS

Figure 1. Scheme of experimental strategy. DNA fragments from the immunoglobulin heavy chain $(\mu)$ enhancer region or from the SV40 enhancer were linked to the promoter (O) of the prokaryotic T7RNAP and reporter sequences from the SV40 virion protein 1 (VP1; solid line). These gene constructs were transferred into the mouse germ line. Fetal livers of mouse embryos transgenic for the microinjected gene construct were isolated, and pre-B cells were immortalized by infection of the cells with A-MuLV. Mosaicism of the transgene was excluded by deriving pre-B cells from $F_{1}$ fetuses or by single-cell cloning pre-B cells from founder fetuses. Accessibility of the T7 promoter in nuclear chromatin was examined by incubating isolated nuclei from transgenic pre-B cells with T7RNAP and analyzing nascent $\mathrm{T} 7$-specific transcripts by $\mathrm{S} 1$ nuclease protection assays. To control for the activity of T7RNAP, reference pre-B cells carrying a different $\mathrm{T} 7$ transgene (see Fig. $2 \mathrm{~B}$ ) were mixed with the test pre-B cells before the isolation of nuclei. The transcriptional state of the transgenes was determined by analyzing total RNA for the presence of VP1 transcripts. The chromatin structure of the transgenes was also examined for the presence of DNase I hypersensitive sites (HS sites). 
T7 RNA polymerase (T7RNAP) as a molecular tool to examine the accessibility of its specific binding site integrated at various positions in nuclear chromatin. Our experimental strategy involved the transfer of reporter gene constructs containing the $\mathrm{T} 7$ promoter alone, or linked to an enhancer, into the mouse germ line (Fig. 1). The accessibility of the introduced T7 promoter in nuclear chromatin can subsequently be examined by the addition of purified T7RNAP to nuclei from immortalized transgenic pre-B cells and by the analysis of the nascent T7-specific transcripts. In this way, the gene constructs are assembled into chromatin during normal development and their accessibility in nuclear chromatin can be analyzed in a homogeneous cell population.

The rationale for using T7RNAP was threefold. First, T7RNAP represents a monomeric protein that recognizes a specific nucleotide sequence (Chamberlin and Ryan 1982). This contrasts the nonspecific interaction of DNase I that has been used extensively to probe changes in chromatin structure. Second, binding of T7RNAP to its promoter does not depend on interaction with other proteins (Chamberlin and Ryan 1982). Thus, promoter recognition by T7RNAP is a direct function of the accessibility of this particular nucleotide sequence. Third, the interaction of T7RNAP with its promoter in nuclear chromatin can be quantitated relatively easily by measuring the synthesis of T7-specific nascent transcripts.

As a paradigm for a developmentally regulated enhancer, we chose the immunoglobulin heavy chain $(\mu)$ enhancer region (Banerii et al. 1983; Gillies et al. 1983). The $\mu$ enhancer region was shown to confer high transcriptional activity on the $\mu$ gene (Jenuwein and Grosschedl 1991) and heterologous genes (Adams et al. 1985) in multiple chromosomal locations in transgenic mice. This functional property of the $\mu$ enhancer region is very reminiscent of an LCR. Moreover, the $\mu$ enhancer region has been characterized in detail. Three functionally distinct elements within the $\mu$ enhancer region have been identified (Fig. 2A). (1) A core element comprising multiple factor binding sites was shown to contain enhancer activity in transient transfection assays with tissue culture cells (Lenardo et al. 1987; Gerster et al. 1987; Ruezinsky et al. 1991; for review, see Libermann and Baltimore 1991); (2) A/T-rich MARs have been identified
Figure 2. Structure of transgenes. $(A) \mathrm{Di}$ agram of the murine immunoglobulin heavy chain $\mu$ enhancer. The enhancer core is represented by a darkly shaded box. Individual factor binding sites are depicted as lightly shaded boxes and include the E-box motifs, the $\mu \mathrm{A}$ element and the $\mu \mathrm{B}$ and OCTA sites (for review, see Libermann and Baltimore 1991). MARs (5'- and 3'flanking) are indicated as open boxes. A cryptic promoter directing heterogeneously initiated transcription in the sense orientation of the $\mu$ transcription unit (Lennon and Perry 1985) is located in the close 3 ' proximity of the OCTA site. The transcripts originating from this promoter are indicated by the arrow labeled sterile $\mu$. Important restriction sites for the generation of enhancer DNA fragments are shown. The numbers refer to approximately one hundredth of the nucleotide positions relative to the mRNA start site of transcription in $\mathrm{p} \mu$ (Grosschedl and Baltimore 1985). (B) Schematic representation of T7-VP1 test and T7-LT reference gene constructs. The synthetic T7 promoter is indicated $(O \mid$. The VP1 and LT reporter sequences, comprising sequences from the SV40 genome, are represented by a bold and thin line, respectively. The construction of the genes is described in Materials and methods. The direction of T7-specific transcription is indicated by an arrow. DNA fragments comprising various parts of the $\mu$ enhancer region were linked to the $\mathrm{T} 7$ promoter in an orientation resulting in

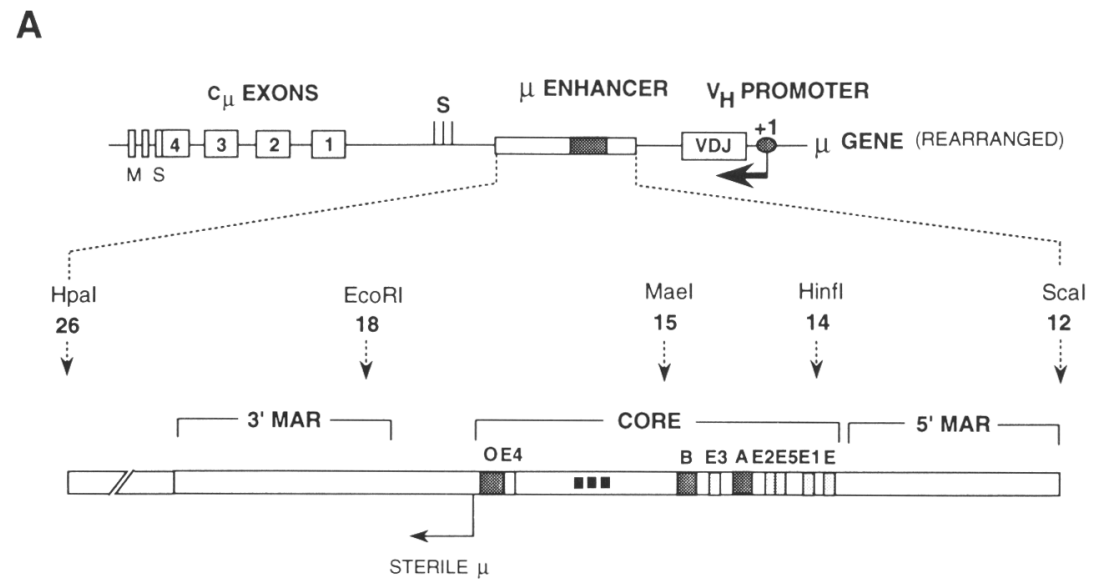

B

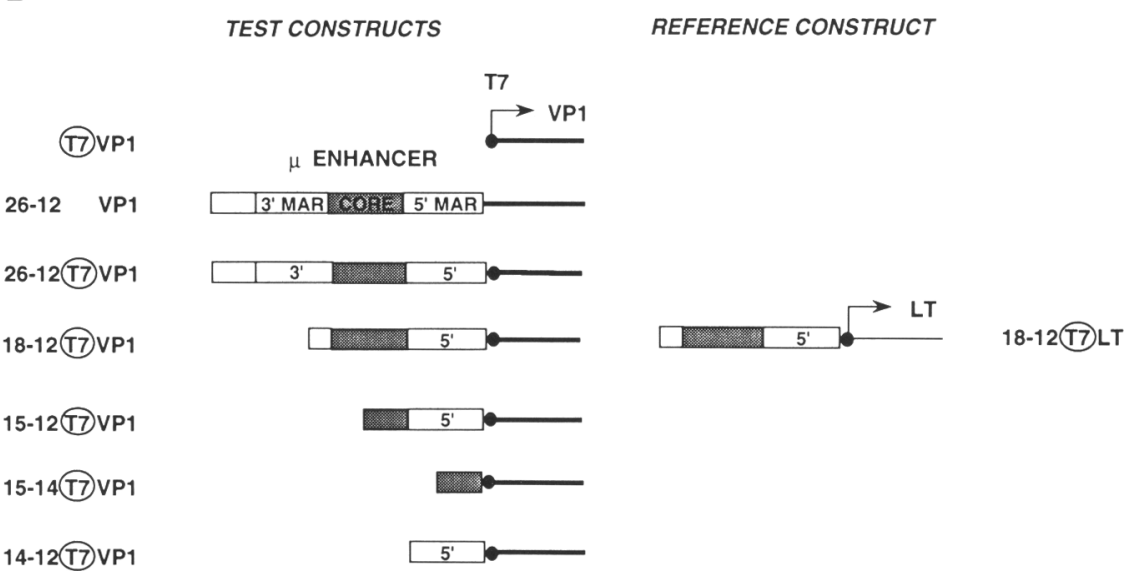
opposite directions of sterile $\mu$ transcription and T7-specific transcription. The nomenclature of the gene constructs indicates the approximate nucleotide boundaries of the $\mu$ enhancer fragments. For microinjection of $\mu \mathrm{T} 7$ constructs into fertilized C57Bl6 $\times$ SJL $\mathrm{F}_{2}$ mouse eggs, the plasmids were released from the vector backbone and the gene inserts were isolated. 
flanking the $\mu$ enhancer core (Cockerill et al. 1987) and were shown recently to affect expression of stably integrated reporter genes (Scheuermann and Chen 1989; Bode et al. 1992); and (3) a cryptic promoter directing the synthesis of "sterile" $\mu$ transcripts has been localized at the 3 ' boundary of the enhancer core (Lennon and Perry 1985; Su and Kadesch 1990). Transcription originating from this cryptic promoter has been proposed to contribute to the accessibility of the $\mu$ locus for gene rearrangement (Blackwell et al. 1986; Ferrier et al. 1990; Schlissel et al. 1991).

The $\mu$ enhancer confers factor access on a heterologous binding site in nuclear chromatin

To examine the potential of the $\mu$ enhancer region to govern accessibility in nuclear chromatin, we linked the $\mathrm{T} 7$ promoter, alone or in combination with the $\mu$ enhancer region, to SV40 virion protein 1 (VP1) reporter sequences (Fig. 2B). Gene constructs were introduced into the mouse germ line, and transgenic pre-B cell lines were derived from fetal livers by transformation with Abelson murine leukemia virus (A-MuLV). For the analysis of the accessibility of the T7 promoter in chromatin, nuclei were isolated and incubated with increasing amounts of T7RNAP. Correctly initiated, nascent T7run-on transcripts were detected by $S 1$ nuclease protection analysis with a DNA probe that protects sequences up to position $+82,3^{\prime}$ from the $\mathrm{T} 7$ promoter (see Fig. $3 \mathrm{C})$. To control for a possible variability in the nuclei preparations, we mixed, prior to the isolation of nuclei, "test" cells containing T7-VP1 transgenes with "reference" cells. The reference gene consists of the $\mu$ enhancer and the $\mathrm{T} 7$ promoter, linked to a different reporter sequence (18-12T7-LT, see Fig. 2B). Detection of these reference transcripts in all reactions can be used as an internal standard for the accessibility of the $\mathrm{T} 7$ promoter in nuclear chromatin.

First, we determined the effect of chromatin on the accessibility of the T7 promoter in the absence of the linked $\mu$ enhancer (lines 2004 and 2015). We compared the synthesis of $\mathrm{T} 7$-specific transcripts from genomic DNA with that from nuclei. Abundant T7-specific tran-
A

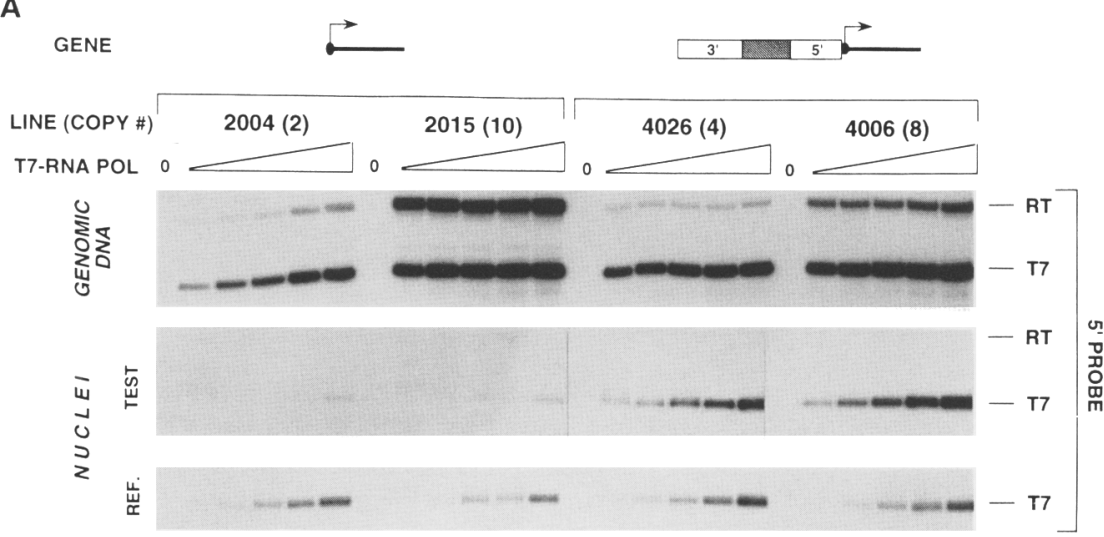

B

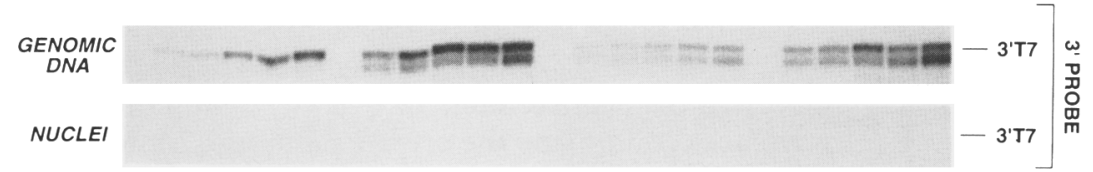

C

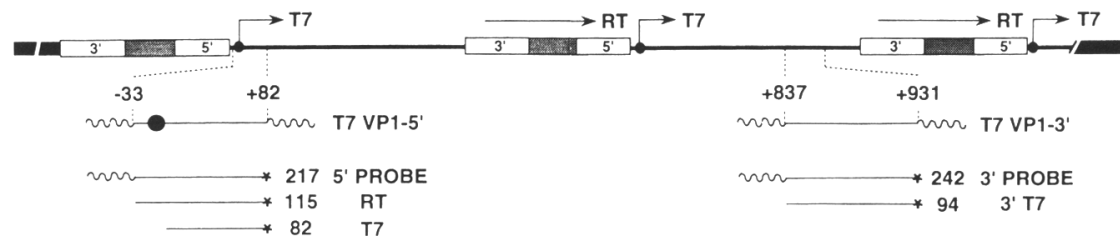

Figure 3. The $\mu$ enhancer antagonizes chromatin-dependent repression of factor access. (A) (Top) S1 nuclease protection analysis detecting T7-specific transcripts derived from genomic transgene DNA. Ten micrograms of genomic DNA, isolated from A-MuLV-transformed transgenic pre-B cells of lines 2004, 2015,4026 , and 4006, was incubated with increasing amounts $10,20,40,80,160$, and 320 units) of T7RNAP. In these and all subsequent experiments, we used conditions for the preparation of nuclei that minimize changes in the in vivo chromatin structure (see Materials and methods). The positions of fragments protected by correctly initiated transcripts (T7) are indicated. RT transcripts derived from head-to-tail cointegrated copies of the transgene are also detected. (Middle) S1 nuclease protection analysis detecting T7-specific transcripts generated by transcription of $1.2 \times 10^{7}$ transgenic pre-B cell nuclei with increasing amounts $(0,40,80$, 160, 320, and 640 units) of T7RNAP. (Bottom) S1 nuclease protection analysis detecting the LT reference transcripts. $(B) \mathrm{S} 1 \mathrm{nu}-$ clease protection analysis detecting $\mathrm{T} 7$ transcripts spanning the region between nucleotides +837 to $+931,3^{\prime}$ of the T7 promoter. For this analysis, we used the same RNA samples as described above. $|C|$ Schematic representation of the DNA probes and protected fragments of S1 nuclease protection analysis. A head-to-tail arrangement of

three transgene copies is shown. The representation of $\mu$ enhancer sequences, the T7 promoter, and the VP1 reporter sequences is the same as in Fig. 2B. Flanking genomic sequences are depicted as a solid bar. The single-stranded DNA probes contain vector sequences (represented by a wavy line) at their $3^{\prime}$ ends to distinguish fragments protected by RT transcripts from the undigested probe. The sizes of the full-length DNA probes and of the fragments protected by the correctly initiated (T7), RT, and $3^{\prime}$ elongated (3'T7) transcripts are indicated. 
scripts were detected by transcribing genomic DNA, with their numbers increasing according to the concentration of T7RNAP (Fig. 3A, top). In contrast, very few T7-specific test transcripts were detected only in nuclei incubated with the highest concentration of T7RNAP (Fig. 3A, middle). Second, we determined the ability of the $\mu$ enhancer region to alter the accessibility of the $\mathrm{T} 7$ promoter in nuclear chromatin (lines 4026 and 4006). As anticipated, the $\mu$ enhancer had no effect on transcription of genomic DNA. However, the $\mu$ enhancer drastically increased the number of $\mathrm{T} 7$-specific test transcripts in nuclei, proportional to the concentration of T7RNAP. These data indicate that factor access established by the $\mu$ enhancer allows T7RNAP to interact productively with its cognate binding site in nuclear chromatin.

This run-on assay requires that T7RNAP both recognizes its promoter and synthesizes at least 82 nucleotides to protect the DNA probe from S1 nuclease digestion. In principle, the $\mu$ enhancer-induced alterations in the chromatin structure could also affect the elongation of transcription by T7RNAP. Two observations, however, suggest that the chromatin structure of the transgene containing the $\mu$ enhancer is incompatible with a processive function of T7RNAP. First, readthrough (RT) transcripts, generated from tandemly integrated transgene copies (data not shown), were detected by transcribing genomic DNA with T7RNAP (Fig. 3A, top). In contrast, these RT transcripts were undetectable in RNA from transcribed nuclei (Fig. 3A, middle). Second, S1 nuclease protection analysis with a VP1-3' DNA probe, comprising sequences located 930 nucleotides downstream from the T7 promoter, failed to detect long T7 transcripts in RNA from transcribed nuclei $\left(3^{\prime} \mathrm{T} 7\right.$, see Fig. 3B,Cl. As expected, these 3'T7 transcripts were detected with transcribed genomic DNA. These data show, in agreement with in vitro transcription of reconstituted templates containing nucleosomal arrays $\left\langle\mathrm{O}^{\prime} \mathrm{Neill}\right.$ et al. 1992), that the elongation of transcripts initiated by T7RNAP is markedly impaired in nuclear chromatin. Thus, the stimulatory effect of the $\mu$ enhancer on T7 transcription is attributable to a facilitated access of T7RNAP to the $\mathrm{T} 7$ promoter rather than to facilitated elongation of transcription. Moreover, these data indicate that the accessibility of each individual copy of tandemly integrated transgenes can be examined independently and, therefore, should not change with an increase in the copy number of trangenes.

Finally, we quantitated the accessibility of the transgene by determining the relative numbers of correctly initiated $\mathrm{T} 7$ transcripts generated from genomic DNA and nuclei and by normalizing these numbers per gene copy (Fig. 4). T7-specific transcripts were generated from genomic DNA carrying enhancerless transgenes at a level $\sim 1000$-fold higher than that in nuclei, confirming the chromatin-mediated limitation of factor access. Moreover, the presence of the $\mu$ enhancer in lines 4026 and 4006 increased T7-dependent transcription in nuclei by a factor of at least 30 . Thus, the $\mu$ enhancer region significantly alters the accessibility of a specific factor binding site in nuclear chromatin.

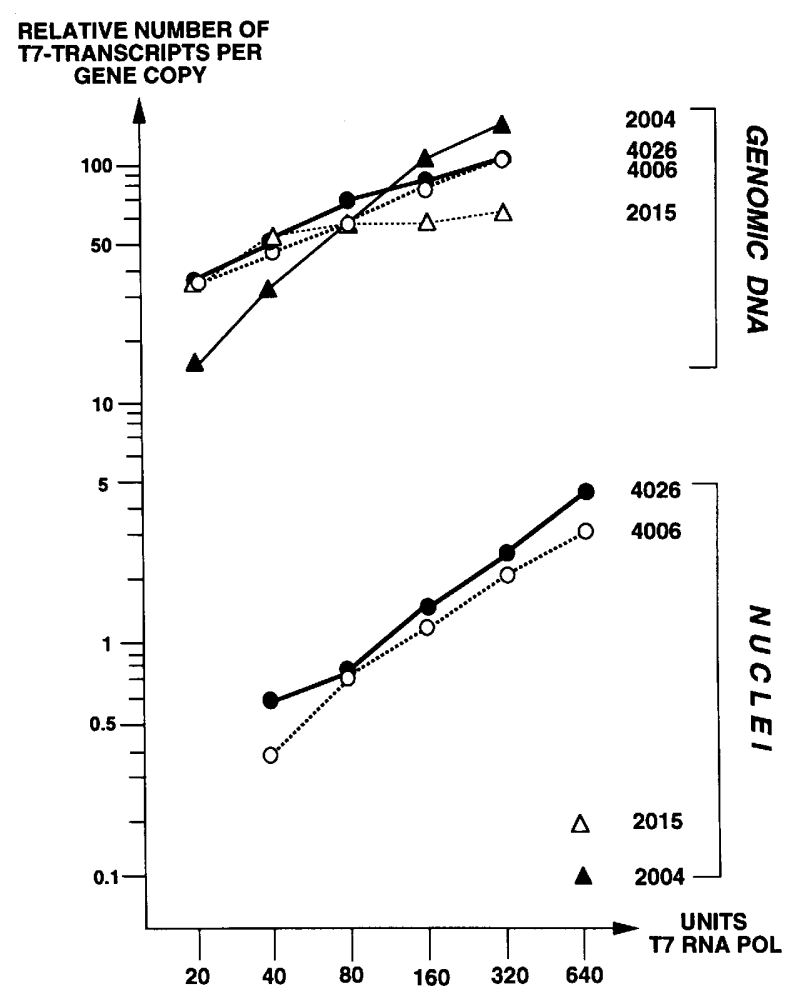

Figure 4. Quantitation of T7RNAP accessibility in nuclear chromatin. Semilogarithmic plot of the relative numbers of T7 transcripts per transgene copy. The numbers of correctly initiated $\mathrm{T} 7$ transcripts (T7) generated by in vitro transcription of genomic DNA and nuclei (see Fig. 3A) were quantitated with a PhosphorImager (Molecular Dynamics). These numbers were then adjusted for differences in the number of gene copies, different number of reference transcripts, different exposure times of the respective autoradiographs and differences in template concentration (see Materials and methods).

\section{Sequence requirements for the establishment} of factor access in nuclear chromatin

With the aim of dissecting the domains of the $\mu$ enhancer region that govern factor access in nuclear chromatin, we linked various fragments of the $\mu$ enhancer region to the $\mathrm{T} 7$ promoter (Fig. $2 \mathrm{~B}$ ). In particular, we deleted the 3'MAR alone or together with enhancer sequences comprising the cryptic promoter. Moreover, we linked a 95-bp enhancer core fragment to the T7 promoter. This enhancer fragment lacks both flanking MAR sequences and sequences comprising the cryptic promoter. Finally, we generated a construct containing only the 5'MAR. For each gene construct, multiple A-MuLVtransformed pre-B cell lines were obtained that carry a similar range of copy numbers of the respective transgenes. The accessibility of the $\mathrm{T} 7$ promoter in nuclear chromatin from mixed pre-B cells was analyzed as decribed above.

In 14 of 15 lines containing gene constructs with $\mu$ enhancer core fragments, incubation of transgenic pre-B cell nuclei with T7RNAP generated T7-specific test transcripts (Fig. 5, middle; lines 4001-220). In contrast, 

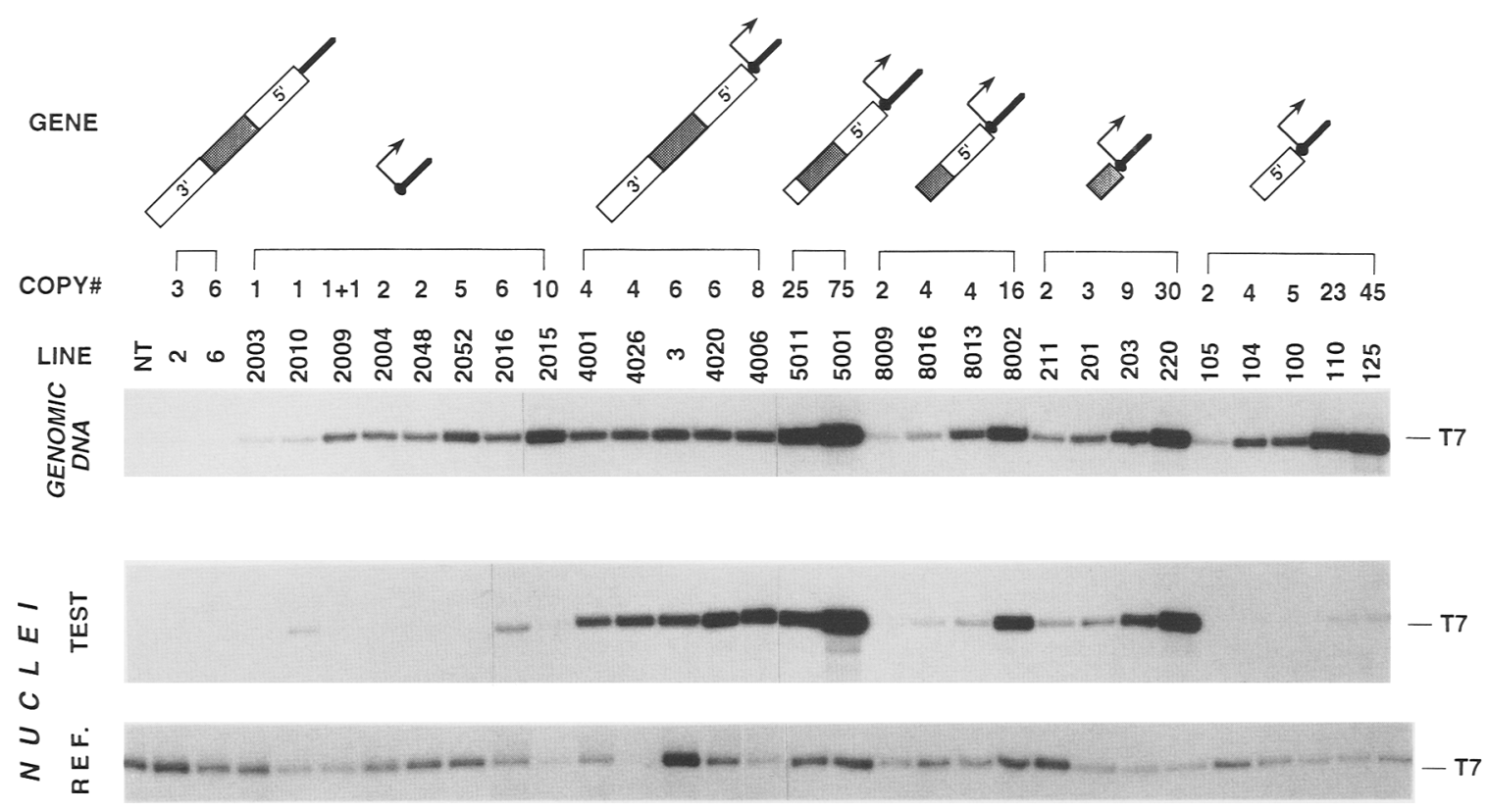

Figure 5. The core element of the $\mu$ enhancer establishes factor access in nuclear chromatin. Individual pre-B cell lines carrying a particular $\mu \mathrm{T} 7$ transgene are grouped together and organized according to increasing copy numbers. Copy numbers were determined by DNA blot analysis (data not shown) and by in vitro transcription of genomic DNA with T7RNAP. (Top) S1 nuclease protection analysis detecting T7-specific transcripts generated by in vitro transcription of $10 \mu \mathrm{g}$ of genomic DNA with 80 units of T7RNAP. (Middle) S1 nuclease protection analysis detecting T7-specific transcripts generated by transcription of $1.2 \times 10^{7}$ transgenic pre-B cell nuclei with 160 units of T7RNAP. On the basis of our previous analysis of T7 transcription of nuclei and genomic DNA (see Fig. 4), we performed the S1 protection analysis with 30 -fold less RNA products generated from genomic DNA as compared with nuclei. (Bottom) S1 nuclease protection analysis detecting T7-specific reference transcripts.

six out of eight lines carrying gene constructs that lack $\mu$ enhancer sequences failed to generate detectable T7 transcripts (lines 2003-2015). The weak accessibility of the T7 promoter in lines 2010 and 2016 is likely due to chromosomal position effects. Similarly, three out of five lines containing the 5'MAR alone linked to the T7 promoter were inactive in generating detectable $\mathrm{T} 7$-transcripts (lines 105-100). Very few T7-specific transcripts, however, were detected in lines 110 and 125 containing high copy numbers of this 5 'MAR-T7 transgene. Thus, the presence of MAR sequences alone is insufficient to confer accessibility upon the $\mathrm{T} 7$ promoter in nuclear chromatin. This contrasts recent observations that MAR-like sequences facilitate the HMGI/Y-mediated antirepression of $\mathrm{T} 7$ transcription by histone $\mathrm{Hl}$ in vitro (Zhao et al. 1993). As a control for the specificity of T7RNAP, no T7 transcripts were detected in lines 2 and 6 , which carry transgenes containing an intact $\mu$ enhancer region but lacking the $\mathrm{T} 7$ promoter. For each transcription reaction in nuclei, the presence of T7-specific reference transcripts was confirmed (Fig. 5, bottom). Together, these results demonstrate that the 95 -bp core element of the $\mu$ enhancer is necessary and sufficient to confer upon a cis-linked heterologous factor binding site accessibility in nuclear chromatin.

To quantitate the accessibility of the $\mathrm{T} 7$ promoter for each individual transgene, we compared the number of T7-specific test transcripts generated in nuclei with that of $\mathrm{T} 7$ transcripts obtained by transcription of genomic DNA (Fig. 5, middle and top, respectively). Because T7 transcription of genomic DNA is more efficient than that of nuclei (see Fig. 4), we used for the S1 protection analysis one-thirtieth of the RNA products derived from genomic DNA as compared with nuclei. The ratio of transcripts generated in nuclei and genomic DNA was constant for most of the transgenes containing the enhancer core. Moreover, the number of $\mathrm{T} 7$ transcripts increased according to the copy number of the transgene. Together, these data indicate that the $\mu$ enhancer confers position-independent accessibility on the linked $\mathrm{T} 7$ promoter, proportional to the number of gene copies.

Comparison of the accessibility of the T7 promoter in the various gene constructs containing the enhancer core, however, indicated some notable differences. First, the removal of the $3^{\prime}$ MAR alone had no effect on T7 transcription in nuclei (lines 5011 and 5001). However, deletion of this element, together with sequences comprising the cryptic promoter, decreased the number of $\mathrm{T} 7$ transcripts by a factor of 3-5 (lines 8016-8013). This low level of transcription is near the limit of detection of T7 transcripts. Therefore, taking into account the differences in the number of transgene copies and reference transcripts between lines 8009 and 8016 , it is difficult to distinguish whether the T7 promoter in line 8009 generates transcripts at some reduced level or whether it is inaccessible. This decrease in accessibility of the $T 7$ pro- 
moter, however, was not observed in line 8002, which carries the transgene integrated in an expressed endogenous locus (see below). This suggests that transcription, although not essential for the recognition of the T7 promoter in nuclear chromatin (see below), may augment the efficiency of DNA binding by T7RNAP. Second, deletion of the 5'MAR, which results in the immediate juxtaposition of the T7 promoter and the 95-bp enhancer core (lines 211-220), increased the accessibility of the T7 promoter two- to threefold relative to transgenes in lines 8009-8002. These observations suggest that accessibility established by the $\mu$ enhancer core may be restricted to a rather local region.

The establishment of factor access can be uncoupled from the process of transcription

One goal of our experimental strategy has been to un- couple the mechanisms regulating factor access in chromatin from the process of transcription. The transcriptional state of the transgenes can be influenced by the activities of promoters in genomic sequences flanking the transgenic loci and by the activity of the cryptic promoter in the transgenic enhancer. Therefore, we examined, by S1 nuclease protection assays, total RNA from all transgenic pre-B cell lines for the presence of transcripts traversing the T7 promoter (Fig. 6). For this RNA analysis, we used single-stranded sense and antisense DNA probes spanning the T7 promoter (Fig. 6B). The sense DNA probe allows the detection of both RT transcripts from flanking genomic sequences and sterile $\mu$ transcripts originating at the cryptic promoter in the transgenic enhancer. The antisense probe not only detects RT transcripts from flanking genomic sequences but also sterile $\mu$ transcripts originating from a gene copy that has integrated in a head-to-head orientation as com-

A
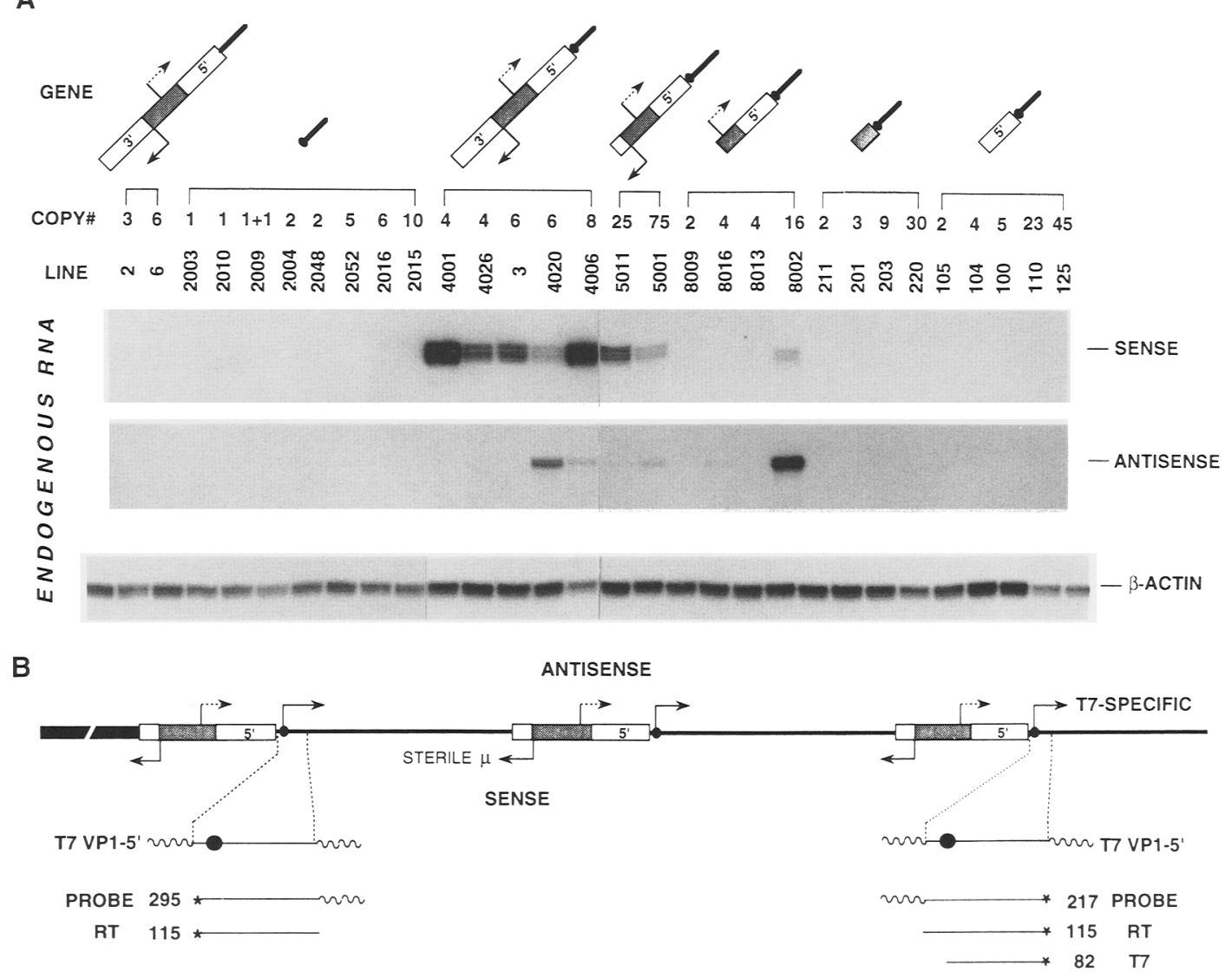

$S E N S E$

ANTI SENSE

Figure 6. Transcriptional state of $\mu \mathrm{T} 7$ transgenes. $(A)$ Detection of $\mu$ enhancer-initiated VP1 transcripts in total RNA isolated from transgenic pre-B cells. Fifteen micrograms of total RNA was analyzed for the presence of sense and antisense transcripts by S1 nuclease protection. To demonstrate the quality and integrity of the RNA preparations, $3 \mu \mathrm{g}$ of total RNA was subjected to an S1 nuclease protection analysis specific for endogenous mouse $\beta$-actin sequences. $(B)$ Schematic representation of probe and protected fragments of $\mathrm{S} 1$ nuclease protection analysis as described in Figure 3C. Sense (solid arrow) and antisense (broken arrow) transcription is defined as shown. Antisense transcription most likely results from cryptic promoter activity at a gene copy integrated in reverse orientation as the normal head-to-tail transgene concatemer and, for reasons of clarity, is indicated at the same enhancer fragment. Antisense transcription of the transgene was analyzed with the same probe also used to detect transcripts correctly initiated at the T7 promoter (solid arrow at dot) by T7RNAP (see Fig. 3C). 
pared with the regular head-to-tail transgene concatenates.

Neither sense nor antisense transcripts were detected in any of the pre-B cell lines lacking the transgenic $\mu$ enhancer, indicating that RT transcription from flanking genomic sequences is a rather infrequent event (eight lines: 2003-2015). In contrast, and as anticipated, sense transcripts were detected at variable levels in transgenic pre-B cells containing $\mu$ enhancer fragments that include the cryptic promoter (seven lines: 4001-5001). Confirming the specificity of the DNA probes, no transcripts were detected in RNA from cell lines 2 and 6, which contain the $\mu$ enhancer region but lack the $T 7$ promoter. Deletion of sequences comprising the cryptic promoter reduced the number of sense transcripts to undetectable levels in three of four lines $(8009,8016$, and 8013), consistent with the ability of the cryptic promoter to direct sense transcription. Antisense transcripts were detected in variable abundance in six of 11 lines containing the $\mu$ enhancer core and one or both MARs (lines 4020, 4006, $5011,5001,8016$, and 8002). The high transcriptional activity of the transgene in line 8002 most likely results from integration into an expressed endogenous gene locus because these transcripts were also found in mouse tissues in which the $\mu$ enhancer is inactive (data not shown). Importantly, transgenes that contain the 95-bp enhancer core alone (five lines: 211-220) or the 5'MAR alone (five lines: 105-125) did not generate detectable sense or antisense transcripts, suggesting that the 95-bp enhancer core element does not impart upon the transgene an active transcriptional state.

To facilitate evaluation of the transcriptional state of the transgenes, we quantitated the number of transcripts generated by endogenous RNA polymerase II and normalized them per gene copy. These data indicated that the numbers of combined endogenous sense and antisense transcripts show a high degree of variability (two orders of magnitude) in the absence of the 3'MAR and/or cryptic promoter (Fig. 7B). In contrast, a similar quantitative representation of transcription with T7RNAP indicated that the numbers of $\mathrm{T} 7$ transcripts, generated per gene copy in 12 of 15 transgenes containing the enhancer core, differed by less than fivefold (Fig. 7A). Importantly, the generation of T7-transcripts did not correlate with an active transcriptional state of the transgene which could be monitored over three orders of magnitude. Together, these data indicate that the establishment of factor access by the 95-bp enhancer core element can be mechanistically uncoupled from the process of transcription.

\section{Establishment of factor access does not correlate} with the formation of DNase I hypersensitive sites

Although the use of T7RNAP allows for the quantitation of the accessibility of a specific binding site in chromatin, it does not measure the overall accessibility of chromatin in the regions surrounding this factor binding site. Therefore, it was of interest to examine the potential of the various $\mu$ enhancer fragments to alter the chromatin

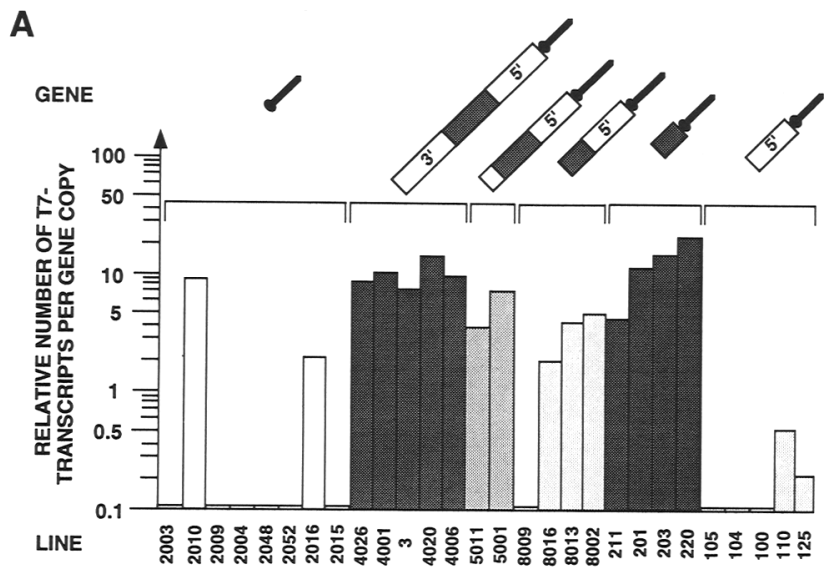

B

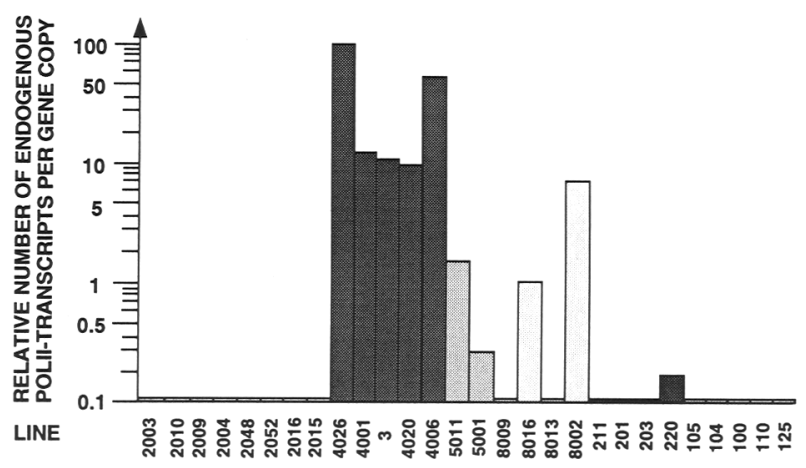

Figure 7. Normalized levels of transcription by T7RNAP and endogenous RNA polymerase II. (A) Semilogarithmic histogram of the relative numbers of $\mathrm{T} 7$ transcripts generated by transcription of nuclei with T7RNAP (see Fig. 5). The numbers of correctly initiated $\mathrm{T} 7$ transcripts (T7) were quantitated with a PhosphorImager (Molecular Dynamics) and adjusted for differences in the number of gene copies and differences in the number of LT reference transcripts. $(B)$ Semilogarithmic histogram of the relative numbers of transgene-specific endogenous RNA polymerase II transcripts (see Fig. 6). The numbers of sense and antisense transcripts were quantitated with a PhosphorImager (Molecular Dynamics) and combined to give the total transcriptional activity of the respective transgene. This total number of transcripts was then normalized for differences in the number of gene copies and differences in the number of the $\beta$-actin control transcripts.

structure at a more general level and to compare the sensitivity of T7RNAP to measure factor access in chromatin with that of DNase I.

For each gene construct shown in Figure 2B, nuclei from representative pre-B cell lines were digested with increasing amounts of DNase I. The intact $\mu$ enhancer region comprising the core enhancer element and $5^{\prime}$ - and 3'-flanking MARs (line 3) generated a cluster of four distinct HS sites (Fig. 8A, top, line 3). This pattern of HS sites was very similar to that observed in the enhancer region of the endogenous $\mu$ gene locus (Fig. 8A, bottom). The two strongest HS sites mapped within the enhancer core, and two weaker HS sites mapped near the cryptic promoter and within the $3^{\prime}$ MAR (Fig. 8B). 
Figure 8. Formation of DNase I hypersensitivity requires the $\mu$ enhancer core element and flanking MAR sequences. (A) (Top) Mapping of DNase I HS sites in various $\mu \mathrm{T} 7$ transgenes. Approximately $1 \times 10^{8}$ nuclei of transgenic A-MuLV-transformed pre-B cells were incubated with increasing amounts of DNase I. As a control $(0)$, nuclei were lysed immediately after preparation. Genomic DNA was extracted and adjusted with nontransgenic DNA to compensate for differences in the copy number of the transgene. Adjusted DNA was digested with ApaI, separated on an agarose gel, transferred to a nylon filter, and hybridized with a randomprimed VP1-DNA probe (see $B$ for structure of $\mu$ enhancer region and DNA probes). The Apal DNA fragment varies in size according to the length of the linked $\mu$ enhancer fragment. Size markers (in bp) are shown at left. Arrows indicate DNase I-generated fragments. The weak hybridization of DNA fragments migrating slower or faster than the ApaI parental transgenic fragment most likely represents DNA fragments generated by cleavage in flanking genomic DNA and/or by partial restriction digestion. (Bottom) Mapping of HS sites in the endogenous $\mu$ enhancer. Twenty micrograms of genomic DNA (not adjusted) of the same DNase I digestions as above was cleaved with HindIII and analyzed by hybridization with a nicktranslated $\mu$ DNA probe. The transgene in line 3 contains the entire $\mu$ enhancer, and thus a 1.3kb fragment hybridizes with the $\mu$ probe. Because the HS sites detected in nuclei of this line (carrying six copies of the transgene) are the sum of DNase I cleavages in both the endogenous and transgenic $\mu$ enhancer, we used approximately sixfold less genomic DNA. $(B)$ Summary of HS sites mapping analysis. A bold arrow indicates a strong site, a thin arrow an intermediate sites, and a broken arrow a weak site.

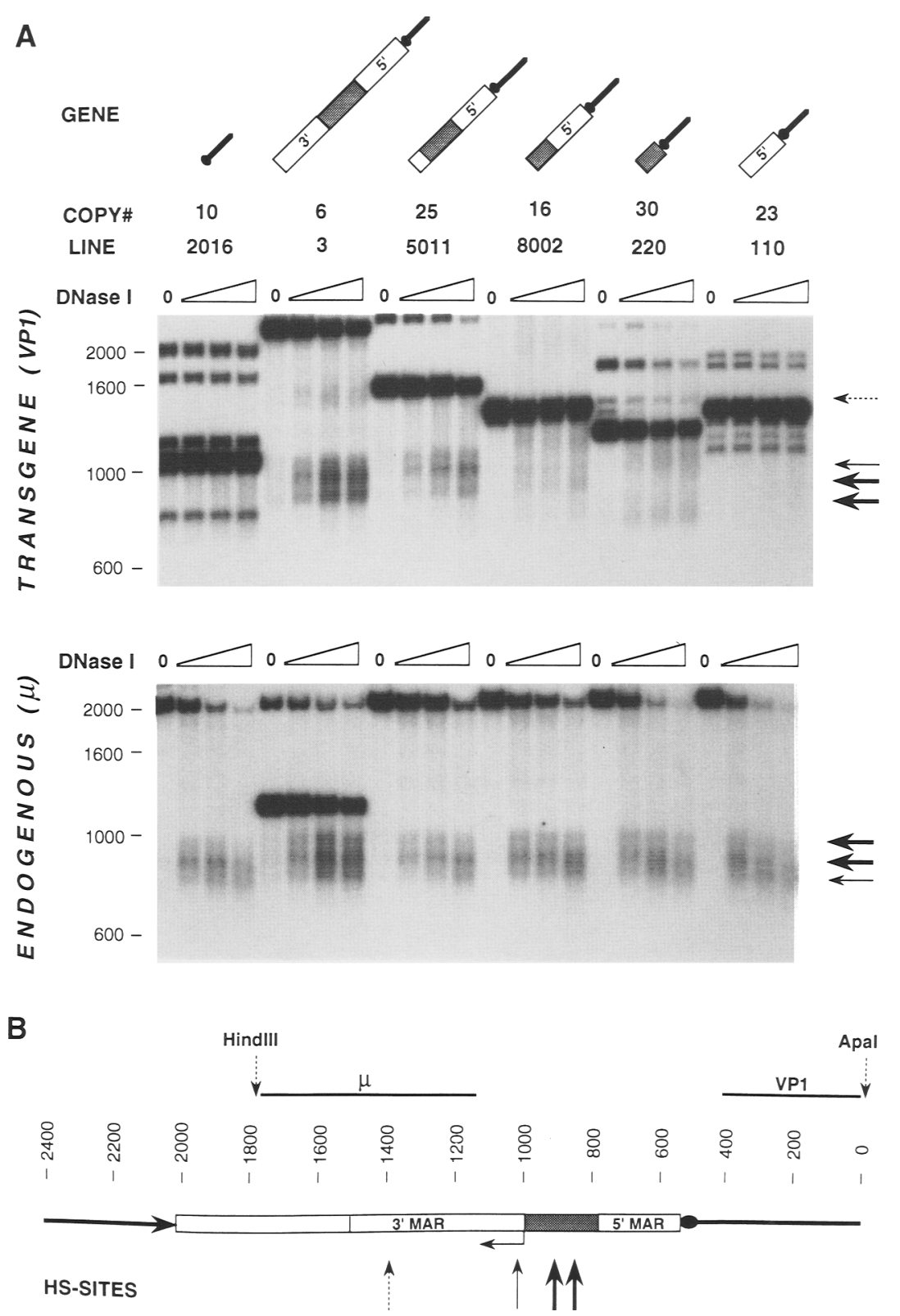

Deletion of the 3'MAR (line 5011) and additional deletion of the cryptic promoter (line 8002) removed their corresponding HS sites and decreased the number of DNase I generated fragments in the $\mu$ enhancer core by a factor of 5 and 20, respectively. Likewise, the degree of DNase I hypersensitivity detected at the 95 -bp $\mu$ enhancer core fragment in line 220 was reduced $>20$-fold relative to the intact $\mu$ enhancer region. In contrast, no HS sites were detected in the transgene containing an isolated 5' MAR (line 110) and in the transgene lacking any $\mu$ sequences (line 2016). To control for similar conditions of DNase I digestion, aliquots of the samples were analyzed for the DNase I hypersensitivity of the endogenous $\mu$ enhancer (Fig. 8A, bottom). The results obtained from the analysis of DNase I hypersensitivity of the various transgenes were confirmed by the additional analysis of another cell line for each gene construct /data not shown). Together, these data indicate that the formation of DNase I HS sites at the $\mu$ enhancer is dependent on the presence of MAR sequences and sequences comprising the cryptic promoter, both of which are virtually dispensable for factor access at the $\mathrm{T} 7$ promoter.

\section{Enhancers differ in their ability to govern factor access in nuclear chromatin}

To investigate whether the ability to establish factor access in chromatin is a general property of transcriptional enhancers, we included in our analysis the SV40 enhancer. This enhancer has been compared extensively 
with the $\mu$ enhancer and was shown to have a similar but distinct arrangement of factor binding sites (Zenke et al. 1986). Moreover, both enhancers display an equivalent potential to stimulate transcription in transient transfection assays in B cells (Schirm et al. 1987; Ondek et al. 1988). In contrast to the $\mu$ enhancer, however, the SV40 enhancer has been shown previously to be virtually nonfunctional in germ-line transformation assays (Brinster et al. 1984).

We generated T7-VP1 and T7-LT reporter gene constructs containing one copy of the 72-bp repeat of the SV40 enhancer, alone or together with the $\mu 5^{\prime} \mathrm{MAR}$. For comparison, we linked two different promoter-proximal regions (comprising sequences upstream of the TATA box) to the T7 promoter. These upstream promoter sequences were derived from the ubiquitously expressed $\beta$-actin and major histocompatibility complex (MHC class I) genes (see Materials and methods). As described above, we analyzed the accessibility of the $\mathrm{T} 7$ promoter by incubating mixed transgenic pre-B cell nuclei with T7RNAP (Fig. 91. T7-specific test transcripts were detected in 4 of 10 lines containing the SV40 enhancer fragment (lines 76, 833, 709, and 725). Thus, the chromosomal position independence of factor access mediated by the SV40 enhancer differs from that of the $\mu$ enhancer (Fig. 9, lines 5053 and 5050; see also Fig. 5). Similar to the 95-bp $\mu$ enhancer core, the SV40 enhancer fragment did not direct sense or antisense transcription (data not shown). This suggests that both a cellular and a viral enhancer can mediate factor access independent of an active transcriptional state of the transgene. The competence of the $\mu$ enhancer to confer factor access, however, was significantly higher than that of the SV40 enhancer, consistent with the different potential of these enhancers to augment transcription from RNA polymerase II promoters in germ-line transformation assays (Adams et al. 1985; Jenuwein and Grosschedl 1991; Brinster et al. 1984). In contrast to these enhancers, the two promoter-proximal regions examined did not generate detectable T7-specific transcripts in nuclei from four lines (lines 6013-6081). Thus, the clustering of multiple factor binding sites in enhancers may be important for the generation of factor access in nuclear chromatin.

\section{Discussion}

Enhancers and LCRs have been implicated in the establishment and maintenance of an active transcriptional state of genes in vivo (Grosveld et al. 1987; Grosschedl and Marx 1988). Stimulation of promoter activity by enhancers has been explained by facilitating factor access in chromatin and by interactions between enhancer- and promoter-bound factors (Serfling et al. 1985; Ptashne 1986). We designed experiments to directly examine the ability of enhancers to establish factor access in transcriptionally inactive nuclear chromatin, independent of interactions between enhancer- and promoter-bound factors. We linked the promoter for the prokaryotic T7RNAP to various immunoglobulin $\mu$ enhancer fragments and examined the accessibility of integrated
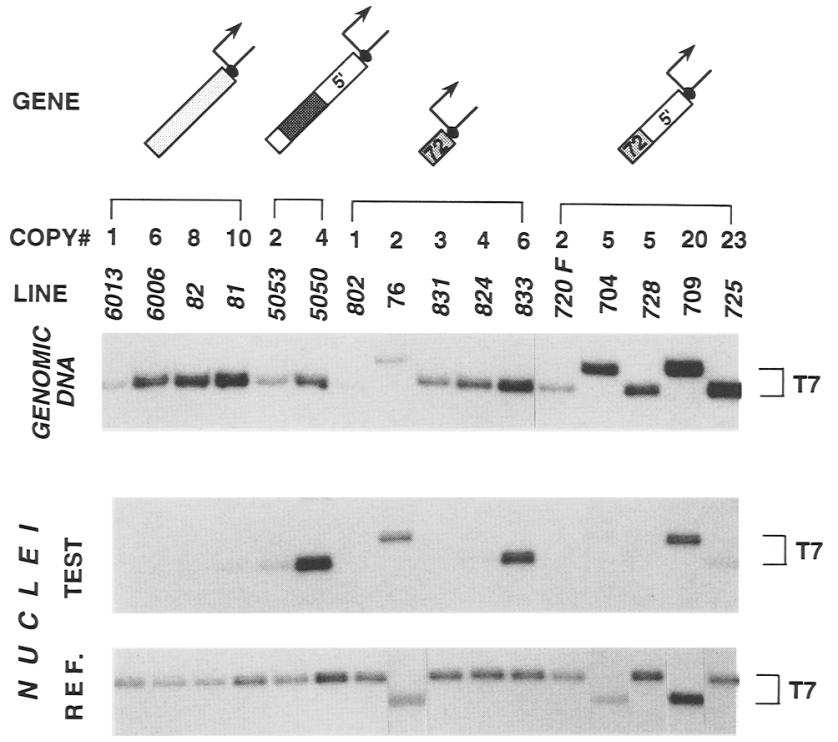

Figure 9. The SV40 enhancer has a reduced ability to mediate factor access in nuclear chromatin. S1 nuclease protection analysis to detect $\mathrm{T} 7$-specific transcripts generated by transcription of the various transgenes with T7RNAP. The structure of the transgenes is shown at the top. Factor binding sites from the MHC class I H2- $\mathrm{K}^{\mathrm{b}}$ promoter-proximal enhancer (lines 6013 and 6006 ) or from the $\beta$-actin promoter-proximal 5 ' region (lines 82 and 81 ) are indicated by a stippled box. One copy of the 72-bp repeats of the SV40 enhancer (shaded box designated 72) is linked to the T7 promoter, alone (five lines: $802-833$ ) or together with the $\mu$ 5'MAR (five lines: 720-725). The construction of the genes is described in Materials and methods. Most of the transgenes contain LT reporter sequences (indicated by designation of the line in italics), and only three have a VP1 reporter (lines 76, 704, and 709). This difference in reporter sequence is reflected by different sizes of fragments protected by VP1 and LT transcripts. Test cells containing T7-LT transgenes were mixed at a $10: 1$ ratio with reference cells containing a T7-VP1 reporter (line 5001). Accordingly, test cells containing T7-VP1 transgenes were mixed at a $2: 1$ ratio with the 1812T7-LT reference cells (line 5050). T7-specific transcripts were generated by transcription of genomic DNA (top) and nuclei (middle and bottom) as described in Fig. 5.

transgenes by incubation of nuclei with T7RNAP or DNase I. These experiments indicated that a $\mu$ enhancer fragment, consisting of enhancer core, cryptic promoter, and flanking MAR sequences, conferred accessibility on the T7 promoter and induced the formation of DNase I HS sites. We delineated the element mediating accessibility of the T7 promoter to a 95-bp enhancer core fragment. This enhancer fragment established accessibility of the $\mathrm{T} 7$ promoter independent of transcription but was not sufficient to induce HS sites. These data suggest a model in which multiple steps are involved in generating an active transcriptional state of a gene locus.

\section{Establishment of sequence-specific factor access in nuclear chromatin}

Our data indicate that $\mu$ enhancer fragments are capable 
of augmenting transcription from a $\mathrm{T} 7$ promoter in nuclear chromatin. Analysis of T7 transcripts demonstrated that the $\mu$ enhancer establishes conditions in nuclear chromatin that are permissive for efficient initiation but not elongation of transcription by T7RNAP. The stimulation of $\mathrm{T} 7$ transcription by the $\mu$ enhancer is most likely the consequence of increased accessibility generated by the $\mu$ enhancer. First, T7RNAP is a sequence-specific DNA-binding protein that does not depend on accessory factors for promoter recognition (Chamberlin and Ryan 1982). Second, transcription by this polymerase does not appear to be stimulated by interaction with eukaryotic enhancer-bound proteins. For example, T7RNAP was shown to be unresponsive to transcriptional stimulation by upstream-bound GAL4 activator protein (Chen et al. 1987). Likewise, T7-dependent transcription was not stimulated by a linked SV40 enhancer in transiently transfected cell lines (W.C. Forrester and R. Grosschedl, unpubl.).

The magnitude of $\mu$ enhancer-mediated stimulation of transcription by T7RNAP in nuclear chromatin is 30 fold. This magnitude of stimulation is significantly lower than the 400 -fold $\mu$ enhancer-mediated increase of transcription by RNA polymerase II in transfected tissue culture cells (Gillies et al. 1983). This quantitative difference can, in principle, be accounted for by multiple functions of the $\mu$ enhancer in the context of a RNA polymerase II promoter. In addition to facilitating factor access, proteins bound at the $\mu$ enhancer are likely to stimulate RNA polymerase II-mediated transcription by protein-protein interactions. Previous experiments in yeast employed a similar assay to examine the role of upstream promoter elements in facilitating factor access. An element comprising $\mathrm{T}$-rich sequences was found to enhance transcription from a $\mathrm{T} 7$ promoter by a factor of 7 (Chen et al. 1987). The same sequences were also shown to augment transcription from a yeast RNA polymerase II promoter in vivo and in vitro, presumably by the binding of a nuclear protein (Lue et al. 1989). This observation is consistent with multiple functions of this sequence element. In contrast to our experiments, the gene linked to the $\mathrm{T} 7$ promoter in the yeast study still retained part of the promoter for RNA polymerase II and involved the continuous expression of T7RNAP (Chen et al. 1987). Thus, the interpretation of these experiments is complicated by the possibilities that factor access to the $\mathrm{T} 7$ promoter is influenced by RNA polymerase IImediated transcription and that T7RNAP may bind the T7 promoter during DNA replication.

Interestingly, the $\mu$ enhancer-mediated accessibility of the $\mathrm{T} 7$ promoter is position independent and the overall levels of $\mathrm{T} 7$ transcripts are proportional to gene copy number. These properties are similar to those of LCRs in regulating RNA polymerase II transcription. The observed position independence of factor access in the presence of the $\mu$ enhancer could be formally explained by the ability of the $\mu$ enhancer to direct integration of the transgene into already accessible chromatin. We consider this as unlikely because the 95-bp enhancer core element was sufficient to confer position-independent accessibility on the $\mathrm{T} 7$ promoter in the context of a transgene that was integrated into transcriptionally inactive and DNase I-insensitive chromatin. Moreover, we used germ-line transformation to assay establishment of accessibility in nuclear chromatin. This mode of gene transfer allows for integration in the earliest stages of embryogenesis, likely before heterochromatinization and the establishment of cell-type specific changes in the chromatin structure. The ability of the 95-bp enhancer core fragment to mediate factor access in the absence of flanking MAR sequences suggests that the detected alteration in the chromatin structure is independent of the insulating effects of "boundary elements" that have been implicated to play a role in organizing chromatin domains (Stief et al. 1989; Kellum and Schedl 1991; McKnight et al. 1992). Finally, accessibility of the T7 promoter was independent of the copy number of integrated transgenes, because we observed a linear relationship between the numbers of $\mathrm{T} 7$-specific transcripts and transgene copies.

In contrast, RNA polymerase II transcripts initiated at the cryptic promoter in the enhancer core (sterile transcripts) were found to be generated at high levels per gene copy only in the context of the entire $\mu$ enhancer region. Deletion of the 3'MAR decreased the level of sterile transcripts by approximately an order of magnitude. Moreover, three of eight lines containing $\mu$ enhancer fragments that comprise the core element but lack the cryptic promoter generated endogenous transcripts at highly variable levels. This position dependence of generation of endogenous transcripts contrasts with the apparent position independence of $\mathrm{T} 7 \mathrm{tran}$ scripts. Possibly, changes in the chromatin structure that are mediated by the $\mu$ enhancer core fragment are sufficient to allow access of the single polypeptide T7RNAP but not of the multi-subunit RNA polymerase II, which is five to six times larger.

\section{General alterations of the chromatin structure}

Accessibility of DNA in nuclear chromatin for interaction with T7RNAP does not strictly correlate with the formation of DNase I HS sites. For example, in the context of the $\mu$ enhancer region linked to the T7-VP1 transgene, deletion of the $3^{\prime} M A R$, together with sequences comprising the cryptic promoter, markedly decreased the formation of DNase I hypersensitivity and the overall sensitivity to DNase I (data not shown). In contrast, these deletions did not significantly alter the accessibility of the T7 promoter for interaction with T7RNAP. Moreover, the 95-bp enhancer core fragment governed access of T7RNAP but was severely impaired in its ability to induce DNase I hypersensitivity. The differential access of T7RNAP and DNase I may be accounted for by differences in the interactions of these enzymes with DNA. In particular, T7RNAP is a sequence-specific DNA-binding protein that, similar to other prokaryotic RNA polymerases (Clark and Felsenfeld 1992), can displace a single nucleosome out of the path of transcription. Possibly, these properties of T7RNAP could facili- 
tate a productive protein-DNA interaction in nuclear chromatin under conditions that are not permissive for binding of the non-sequence-specific DNase I. Taken together, our data suggest that access of T7RNAP is dependent only on subtle changes in chromatin that may precede the formation of HS sites.

The apparent differences in $\mathrm{T} 7$ accessibility and DNase I hypersensitivity can be explained by multiple schemes. First, DNase I hypersensitivity may require full occupancy of all factor binding sites present in the enhancer core, whereas access to the $\mathrm{T} 7$ promoter may be possible by partial occupancy of factor binding sites. According to this scheme, full occupancy of factor binding sites in the enhancer core would depend on other sequences in the $\mu$ enhancer region such as MARs flanking the enhancer core. MARs have been shown to mediate association of DNA to the nuclear matrix in vitro (Gasser and Laemmli 1986; Cockerill et al. 1987; Jarman and Higgs 1988) and were proposed to facilitate decondensation of chromatin by providing preferred target sites for proteins displacing histone $\mathrm{Hl}$ (Käs et al. 1993; Zhao et al. 1993). However, we favor a second scheme. The lack of DNase I hypersensitivity associated with enhancer fragments may be related to the absence of enhancer core sequences that comprise the cryptic promoter. Our data indicate a good correlation between the appearance of DNase I hypersensitivity at the transgenic $\mu$ enhancer and the presence of enhancer-initiated sterile transcripts. Transcription per se, however, does not appear to substitute for the lack of the cryptic promoter in inducing HS sites at the $\mu$ enhancer. This interpretation is supported by the analysis of line 8002 , which lacks detectable DNase I HS sites at the enhancer but contains abundant RT transcripts from flanking genomic sequences. Thus, generation of a DNase I HS site at the $\mu$ enhancer may reflect initiation events associated with the cryptic promoter. Recently, position-independent formation of DNase I HS sites at a transgenic chicken $\beta^{A}$-globin enhancer was found to require the presence of the cis-linked promoter (Reitman et al. 1993).

A correlation between DNase I hypersensitivity and transcriptional activity has been reported for hormoneinducible genes. The temporal pattern of the appearance and disappearance of DNase I hypersensitivity at the enhancer of the tyrosine aminotransferase gene has been shown to parallel that of hormonal stimulation of gene transcription (Reik et al. 1991). Although some previous reports suggested the possibility of the formation of DNase I hypersensitivity in the absence of transcription, these reports focused primarily on the utilization of a promoter distant from the HS site and did not address the possibility of transcripts originating near the HS site (Forrester et al. 1987; Blom van Assendelft et al. 1989; Ford et al. 1992). The appearance of $\mu$ enhancer-initiated transcripts not only correlates with stimulation of a distal RNA polymerase II promoter but also with the stimulation of recombination of immunoglobulin gene segments (Blackwell et al. 1986; Ferrier et al. 1990; Schlissel et al. 1991).

In contrast to the formation of DNase I HS sites, al- terations in the chromatin structure that can be detected by access of T7RNAP are independent of measurable transcription over a range of three orders of magnitude. This uncoupling of changes in chromatin structure and transcription is consistent with recent experiments in yeast. These experiments indicated that genetically induced changes in the chromatin structure at a promoter could be detected irrespective of a marked decrease in the level of transcription caused by deletion and mutation of promoter elements (Hirschhorn et al. 1992; Lee and Garrard 1992).

\section{Enhancer function in nuclear chromatin}

The comparison of the $\mu$ enhancer with the SV40 enhancer demonstrates that enhancers differ in their potential to establish factor access during normal cell development. The $\mu$ enhancer can confer accessibility on the $\mathrm{T} 7$ promoter at multiple positions in chromatin of pre-B cells, whereas the SV40 enhancer has a reduced ability to facilitate factor access. Both enhancers have a similar number of factor binding sites and equivalent potential to stimulate an RNA polymerase II promoter in transient transfection studies in B cells (Schirm et al. 1987; Ondek et al. 1988). However, these enhancers differ from each other in the presence of specific factor binding sites. In particular, the $\mu \mathrm{A}, \mathrm{E} 3$, and $\mu \mathrm{B}$ sites, which are targets for members of the helix-loop-helix and Ets families of DNA-binding proteins, are present only in the $\mu$ enhancer. Recently, the combination of these factor binding sites was shown to be important for enhancer function in a transient transfection assay ( $\mathrm{Ru}-$ ezinsky et al. 1991; Nelsen et al. 1993/. The observed difference between the $\mu$ and SV40 enhancers in our assay is also consistent with recent findings suggesting that only specific combinations of transcription factor binding sites derived from the human $\beta$-globin LCR allow for position-independent transcription of transgenes (Talbot et al. 1990; Caterina et al. 1991; Philipsen et al. 1993).

\section{Mechanisms underlying enhancer-mediated factor access}

Enhancer-mediated access of the T7 promoter can be accounted for by several mechanisms. First, occupancy of binding sites in the enhancer core interferes with the presence of a nucleosome. This interpretation is consistent with the observation that the SV40 enhancer resides in a nucleosome-free region in minichromosomes (Varshavsky et al. 1979; Saragosti et al. 1980). Second, the enhancer core fragment facilitates factor access by positioning nucleosomes. Nonrandom positioning of nucleosomes in regulatory regions has been shown to allow binding of transcription factors and facilitates proteininduced displacement of nucleosomes (Piña et al. 1990; Archer et al. 1991). We consider nucleosome positioning, however, as unlikely to account for our data, because we observed accessibility of the $\mathrm{T} 7$ promoter in at least three different positions relative to the $\mu$ enhancer core. 
The $\mathrm{T} 7$ promoter located immediately adjacent to the enhancer core directed a similar level of transcription by T7RNAP as the $T 7$ promoter, which was placed adjacent to the 5'MAR, $220 \mathrm{bp}$ apart from the enhancer core. Moreover, preliminary experiments, in which we moved the T7 promoter $1-\mathrm{kb}$ downstream of the $\mu$ enhancer, indicated that the $\mathrm{T} 7$ promoter was fully accessible (data not shown). Likewise, we detected no significant difference in the relative accessibility of the $\mathrm{T} 7$ promoter directly juxtaposed to the SV40 enhancer or separated from this enhancer by the $\mu 5^{\prime}$ MAR.

The question arises as to how enhancer-binding factors gain access in the first place. Certain transcription factors have been shown to be capable of binding nucleosomal DNA in vitro (Taylor et al. 1991). Cooperative interaction of such transcription factors with other DNA-binding proteins could lead to destabilization of the histone octamer and finally to the displacement of a nucleosome (Workman and Kingston 1992). Passage of a replication fork may be an alternative mechanism underlying the establishment of factor access (for review, see Svaren and Chalkley 1990; Wolffe 1992). The removal of histone octamers during replication would allow for a competition between binding of histones and nonhistone proteins to DNA. Evidence for such a model is provided by several observations. DNA replication in a Xenopus extract has been shown to facilitate the assembly of a functional transcription complex on 5S DNA (Almouzni et al. 1990). Moreover, the timing of replication of the $\beta$-globin locus was found to be different for the transcriptionally active and inactive state of the gene (Forrester et al. 1990). In this regard, it is interesting to note that recent experiments identified an origin of replication in the vicinity of the $\mu$ enhancer region (Ariizumi et al. 1993). Our data, however, indicate that one copy of the 72-bp repeat of the SV40 enhancer, lacking a functional origin of replication, is capable of mediating access to the linked T7 promoter at half of the chromosomal integration sites. Thus, a colocalization of an origin of replication with an enhancer fragment does not seem to be neccessary to establish accessibility in nuclear chromatin.

\section{Local vs. long-range accessibility}

One hallmark of enhancers and LCRs is the function over large distances. Although we have identified the $\mu$ enhancer core as an element that is sufficient to establish a local alteration in the chromatin structure, it is still unclear whether this element can confer accessibility at a distance. Preliminary data suggest that the entire $\mu$ enhancer region, comprising enhancer core, cryptic promoter and flanking MARs, can confer accessibility on the $\mathrm{T} 7$ promoter at a distance of at least $1 \mathrm{~kb}$ from the enhancer ( $T$. Jenuwein and R. Grosschedl, unpubl.). We do not know at present, however, to what extent the cryptic promoter and/or MAR sequences are involved in the establishment of long-range accessibility. Analysis of transgenic mice carrying a mutated rearranged immunoglobulin heavy-chain gene, from which only the MARs flanking the enhancer core have been removed, indicated that expression from the distal $V_{H}$ promoter was severely impaired. In contrast, expression from the cryptic promoter in the enhancer region was reduced only slightly (W.C. Forrester, T. Jenuwein, C. van Genderen, and $\mathrm{R}$. Grosschedl, in prep.). These data are consistent with a model in which the MAR sequences are dispensable for short-range accessibility but would be important for long-range alterations in the chromatin structure.

In conclusion, our data indicate that the $\mu$ enhancer region establishes factor access in nuclear chromatin and suggest a model in which the generation of an active transcriptional state of a gene locus involves multiple steps. An early step would consist of "programming" chromatin by multiple factor binding sites present in the $\mu$ enhancer core. This step, which can be detected by the accessibility of a linked T7 promoter, is independent of measurable transcription and does not lead to the formation of pronounced DNase I HS sites. A subsequent step would consist of additional structural alterations in chromatin at the enhancer that can be detected by DNase I digestion. Possibly, this step requires the function of the cryptic promoter which, together with the MAR, potentiates the enhancer to interact with a distant promoter.

\section{Materials and methods}

Plasmid constructions for $T 7$ transgenes containing $\mu$ enhancer sequences

A synthetic T7 promoter (New England Biolabs) was inserted into the HincII site of pUC18, and the orientation of the $\mathrm{T} 7$ promoter was confirmed by sequencing (pT7). A 951-bp PvuIIHpaI fragment containing SV40 virion 1 (VP1) sequences from map position 1715-2666 (Buchman et al. 1981) in SV40 was introduced into the SmaI site of pT7 in an orientation that allows T7RNAP to start from position 1715 and elongate through position $2666\left(\mathrm{pT} 7_{18}\right)$. Subsequently, the HindIIIAsp 718 fragment from $\mathrm{pT} 7_{18}$ containing the $\mathrm{T} 7$ promoter and flanking VP1 reporter sequences was subcloned into Bluescript $\mathrm{M} 13$ + KS (Stratagene) to give construct T7 VP1 (see Fig. 2). For the reference construct containing SV40 T antigen (LT) reporter sequences, a 943-bp BamHI-HindIII fragment from map position 2533-3476 in SV40 was used, following a similar cloning strategy as outlined for $\mathrm{T} 7_{\mathrm{VP1}}$. The LT sequences were introduced in an orientation that allows T7RNAP to start from position 3476 and elongate through position 2533 (T7 $7_{\text {LT }}$ ). $\mu$ Intragenic sequences were subcloned from $\mathrm{p} \mu$ (Grosschedl and Baltimore 1985), and the respective enhancer fragments (see Fig. 2A) were isolated, introduced into the EcoRV site of $T 7_{\mathrm{VP} 1}$ or $\mathrm{T} 7_{\mathrm{LT}}$, and analyzed for their correct orientation. The boundaries of the various enhancer fragments were confirmed by sequencing.

Plasmid constructions for T7 transgenes containing SV4O enhancer and $\beta$-actin or MHC class I promoter-proximal sequences

Partially overlapping synthetic oligonucleotides encoding SV40 enhancer sequences from map position 185-276 (numbering according to Buchman 1981) were annealed and extended with Klenow DNA polymerase (Boehringer Mannheim). The result- 
ant double-stranded DNA fragments were purified by gel electrophoresis and cloned upstream of the $\mathrm{T} 7$ promoter in $\mathrm{T} 7_{\mathrm{LT}}$ or $\mathrm{T} 7 \mathrm{vP}_{\mathrm{VP}}$ (see above) in an orientation placing nucleotide position $2765^{\prime}$ adjacent to the T7 promoter $\left(\mathrm{SVT}_{\mathrm{LT}}\right.$; transgenic lines $802,831,824$, and 833 ; see Fig. 9). The authenticity of the SV40 enhancer was confirmed by sequencing. To generate constructs SV14-12T7 $7_{\text {LT }}$ (transgenic lines 720,728 , and 725 ) or SV14 $127_{\text {vpl }}$ (transgenic lines 704 and 709), a ScaI-HinfI 5'MAR fragment form the $\mu$ enhancer (see Fig. 2A) was introduced between the T7 promoter and the SV40 enhancer, placing the ScaI site immediately $5^{\prime}$ to the $\mathrm{T} 7$ promoter. To generate the construct containing factor-binding sites present in the murine MHC class I $\mathrm{H} 2-\mathrm{K}^{\mathrm{b}}$ promoter-proximal enhancer, the sequence $5^{\prime}$ GATCAC, located at position -63 to -57 upstream of the start site in the $\mathrm{H} 2-\mathrm{K}^{\mathrm{b}}$ gene (Kimura et al. 1986), was converted to an EcoRV site by site-directed mutagenesis. Subsequently, the 597-bp EcoRV-PstI fragment comprising sequences from map position -60 to -657 was cloned upstream of the T7 promoter in $\mathrm{T}_{\mathrm{LT}}$ in an orientation placing nucleotide position $-6575^{\prime}$ adjacent to the $\mathrm{T} 7$ promoter $\left(\mathrm{H} 2 \mathrm{~T} 7_{\mathrm{LT}}\right.$; transgenic lines 6013 and 6006; see Fig. 9). To generate the construct containing factor binding sites present in the human $\beta$-actin promoterproximal 5' region, a 1151 -bp XhoI-SphI fragment comprising sequences from positions -11 to -1162 upstream of the transcriptional start site (Leavitt et al. 1984) was cloned $5^{\prime}$ to the T7 promoter in $\mathrm{T} 7_{\mathrm{LT}}$ in an orientation placing nucleotide position $-11625^{\prime}$ adjacent to the T7 promoter $\left(\beta T 7_{L T}\right)$. Subsequently, a ScaI-HinfI 5'MAR fragment form the $\mu$ enhancer (see Fig. 2A) was introduced between the T7 promoter and the $\beta$-actin promoter-proximal $5^{\prime}$ region, placing the $S c a I$ site immediately 5' to the T7 promoter $\mid \beta 14-12 T 7_{L T}$; transgenic lines 82 and 81 ; see Fig. 9).

\section{Establishment of clonal transgenic pre-B cells}

Fetal liver cells from embryos at day 16-17 of gestation were infected with A-MuLV present in the supernatant of cell line N54 (kindly provided by D. Baltimore) as described (Rosenberg and Baltimore 1976). Transgenic pre-B cell cultures were identified by blot analysis of fetal head DNA and confirmed by blot analysis of genomic DNA isolated from the established cell lines. Pre-B cell cultures from fetal livers of founder embryos were subcloned by limited dilution.

\section{Transcription of nuclei with T7 RNA polymerase}

Approximately $1 \times 10^{8}$ A-MuLV-transformed transgenic pre-B cells were mixed at a $2: 1$ ratio with reference cells, washed in PBS $^{-}$(CMF, GIBCO) and resuspended in $3 \mathrm{ml}$ hypotonic permeabilization buffer (HP-20: $20 \mathrm{~mm}$ Tris at $\mathrm{pH} 8.0,20 \mathrm{mM} \mathrm{KCl}$, $8 \mathrm{mM} \mathrm{MgCl}_{2}, 1 \mathrm{mM} \mathrm{CaCl}, 2 \mathrm{mM}$ DTT, $2 \mathrm{mM} \mathrm{NaCl}, 0.3 \mathrm{M}$ sucrose, $0.2 \% \mathrm{NP}-40$ ). Cell membranes were broken up by repeated (approximately eight times) pipetting. After $2 \mathrm{~min}$ of incubation on ice, crude nuclei were washed in buffer $\mathrm{T}$ (same as buffer HP-20, but lacking the detergent), counted in a hemocytometer, and adjusted at a concentration of $9 \times 10^{7}$ nuclei/ $\mathrm{ml}$. Two hundred microliters $\left(1.8 \times 10^{7}\right.$ nuclei, representing the $2: 1$ ratio of test vs. reference nuclei) were transcribed for 25 min at $37^{\circ} \mathrm{C}$ in buffer $\mathrm{T}$ immediately after preparation. Transcription was started by the addition of ribonucleotides (rNTPs: $8 \mu \mathrm{l}$ of a $25 \mathrm{~mm}$ stock) and 160 units of T7RNAP (U.S. Biochemical). RNA was subsequently isolated using acidic phenol (Sambrook et al. 1989|. Our isolation/transcription buffer lacks the polyamines spermine and spermidine, and we did not observe discrepancies in the transcription of nuclear chromatin present in isolated nuclei or permeabilized cells (data not shown). Sim- ilar conditions were shown to preserve the authenticity of DNase I footprints in isolated nuclei versus permeabilized cells (Pfeifer and Riggs 1991).

\section{Transcription of genomic DNA with T7 RNA polymerase}

For in vitro transcription of genomic DNA, $10 \mu \mathrm{g}$ of genomic DNA was resuspended in $100 \mu$ l of buffer $T_{D N A}$ (same as buffer $\mathrm{T}$ above, but also containing $2 \mathrm{~mm}$ spermidine and $50 \mu \mathrm{g} / \mathrm{ml}$ of BSA). rNTPs were added, and the DNA was transcribed with 80 units of T7RNAP for $20 \mathrm{~min}$ at $37^{\circ} \mathrm{C}$. The reaction was stopped, and RNA was isolated in the presence of $20 \mu \mathrm{g}$ of yeast tRNA (Sigma) using acidic phenol.

Quantitative comparison of T7-specific transcripts generated from naked DNA and nuclear chromatin

The numbers of T7-specific transcripts generated in the transcription reactions with genomic DNA and nuclei (Fig. 3) were quantitated with a PhosphorImager (Molecular Dynamics). These numbers were then adjusted for differences in the number of gene copies and different exposure times of the respective autoradiographs (fivefold longer exposure for the transcription reactions with nuclei). Furthermore, because the average mammalian genome contains $\sim 5 \times 10^{-6} \mu \mathrm{g}$ of DNA per cell, the transcription reactions with $1.2 \times 10^{7}$ nuclei contain approximately sixfold more $\mathrm{T} 7$ templates as compared with the transcription reactions with $10 \mu \mathrm{g}$ of genomic DNA. Therefore, the numbers of T7-specific transcripts obtained after transcription of genomic DNA were multiplied by a combined factor of 30 .

\section{DNA probe preparations for $S 1$ nuclease protection assays}

A 115-bp HindIII-EcoRI fragment from T7 $7_{\mathrm{VP}}$ comprising the $\mathrm{T} 7$ promoter and $3^{\prime}$ adjacent VPl reporter sequences or a 166-bp BamHI-Asp 718 fragment from T7 ${ }_{\mathrm{VP} 1}$ comprising reporter sequences from the $3^{\prime}$ end of VP1, were subcloned into pUC18 (see Figs. $3 \mathrm{C}$ and $6 \mathrm{~B}$ ). These plasmids served as double-stranded templates for the generation of the different S1 probes. Approximately 6 pmoles of the respective ${ }^{32} \mathrm{P}-5^{\prime}$-end-labeled oligonucleotides (see below) were added to 3 pmoles of alkali-denatured plasmid DNA. The solution was neutralized with $\mathrm{NH}_{4} \mathrm{OAc}$, the DNA/primer was precipitated and resuspended in restriction buffer $150 \mathrm{~mm}$ Tris at pH 7.5, $100 \mathrm{mM} \mathrm{NaCl}, 10 \mathrm{mM} \mathrm{MgCl}_{2}, 1 \mathrm{mM}$ DTT). Deoxyribonucleotides (dNTPs) were added to a final concentration of $0.5 \mathrm{mM}$, and the primer was extended with Klenow DNA polymerase (Boehringer Mannheim) in the presence of the restriction enzyme PvulI. Reaction products were separated on a sequencing gel, and the full-length $S 1$ probes were isolated. The primer for the generation of the $5^{\prime} \mathrm{VPl}$ probe $\left(5^{\prime}\right.$ probe, see Fig. $3 \mathrm{C}$ ) or of the antisense probe (see Fig. 6B) was an 18-bp oligonucleotide (5'-GCCACACTGTAGCAAGGC) complementary to map positions 1779-1762 (Buchman et al. 1981) in SV40. The primer for the generation of the $3^{\prime} \mathrm{VP} 1$ probe $\left(3^{\prime}\right.$ probe, see Fig. 3C) was a 22-bp oligonucleotide (5'-GCAATAGCATCACAAATTTCAC) complementary to map positions 26312610 , located $25 \mathrm{bp} 5^{\prime}$ to the late polyadenylation signal in SV40. The primer for the generation of the sense VPl probe (see Fig. 6B) was a 21-bp oligonucleotide (5'-CCTGCAGGTCTAATACGACTC) partially identical to the $5^{\prime}$ half of the $\mathrm{T} 7$ promoter (sequence in italics). The primer for the generation of the 5'LT probe to detect T7 reference transcripts was a $25-\mathrm{bp}$ oligonucleotide $\quad\left(5^{\prime}\right.$-GCTACTCCTAGCTCAAAGTTCAGCC) identical to map positions $3427-3451$ in SV40. The primer for the generation of the $S 1$ probe to detect endogenous mouse $\beta$-actin transcripts was a 21-bp oligonucleotide (5'-GGCCATC- 
TCCTGCTCGAAGTC) complementary to sequences in the 3' half of a mouse cDNA clone (Alonso et al. 1986).

\section{S1 nuclease protection assays}

Total RNA from A-MuLV-transformed pre-B cells or from isolated nuclei was hybridized with the appropriate DNA probes for $16 \mathrm{hr}$ in the presence of $20 \mu \mathrm{g}$ of yeast tRNA (Sigma) at $37^{\circ} \mathrm{C}$. Treatment of RNA-DNA hybrids with S1 nuclease and analysis of the protected fragments were performed as described (Jenuwein and Grosschedl 1991).

\section{Analysis of DNase I HS sites}

Digestions of nuclei with increasing amounts of DNase I were performed as described (Forrester et al. 1990).

\section{Acknowledgments}

We are grateful to Drs. Mark Groudine, Kelly LaMarco, Jim Kadonaga, and Keith Yamamoto for their critical comments on the manuscript. T.J. was a recipient of a special postdoctoral fellowship from the Leukemia Society of America, and W.C.F. was supported by a National Institutes of Health (NIH) postdoctoral fellowship. This work was supported by a grant from the NIH to R.G.

The publication costs of this article were defrayed in part by payment of page charges. This article must therefore be hereby marked "advertisement" in accordance with 18 USC section 1734 solely to indicate this fact.

\section{References}

Adams, J.M., A.W. Harris, C.A. Pinkert, L.M. Corcoran, W.S. Alexander, S. Cory, R.D. Palmiter, and R.L. Brinster. 1985. The c-myc oncogene driven by immunoglobulin enhancers induces lymphoid malignancy in transgenic mice. Nature 318: $533-538$.

Almouzni, M., M. Méchali, and A.P. Wollfe. 1990. Competition between transcription complex assembly and chromatin assembly on replicating DNA. EMBO /. 9: 573-582.

Alonso, S., A. Minty, Y. Bourlet, and M. Buckingham. 1986. Comparison of three actin coding sequences in the mouse; evolutionary relationships between the actin genes of warmblooded vertebrates. I. Mol. Evol. 23: 11-22.

Archer, T.K., M.G. Cordingley, R.G. Wolford, and G.L. Hager. 1991. Transcription factor access is mediated by accurately positioned nucleosomes on the mouse mammary tumor virus promoter. Mol. Cell. Biol. 11: 688-698.

Ariizumi, K., Z. Wang, and P.W. Tucker. 1993. Immunoglobulin heavy chain enhancer is located near or in an initiation zone of chromosomal DNA replication. Proc. Natl. Acad. Sci. 90: 3695-3699.

Banerii, J., J. Olson, and W. Schaffner. 1983. A lymphocyte-specific cellular enhancer is located downstream of the joining region in immunoglobulin heavy chain genes. Cell 33: 729740.

Becker, P., S. Ruppert, and G. Schütz. 1987. Genomic footprinting reveals cell type-specific DNA binding of ubiquitous factors. Cell 51: 435-443.

Blackwell, T.K., M.W. Moore, G.D. Yancopoulos, H. Suh, S. Lutzker, E. Selsing, and F.W. Alt. 1986. Recombination between immunoglobulin variable region gene segments is enhanced by transcription. Nature 324: 585-589.

Blom van Assendelft, G., O. Hanscombe, F. Grosveld, and D.R.
Greaves. 1989. The $\beta$-globin dominant control region activates homologous and heterologous promoters in a tissuespecific manner. Cell 56: 969-977.

Bode, J., Y. Kohwi, L. Dickinson, T. Joh, D. Klehr, C. Mielke, and T. Kohwi-Shigematsu. 1992. Biological significance of unwinding capability of nuclear matrix-associating DNAs. Science 255: 195-197.

Brinster, R.L., H.Y. Chen, A. Messing, T. van Dyke, A.J. Levine, and R.D. Palmiter. 1984. Transgenic mice harboring SV40 $\mathrm{T}$-antigen genes develop characteristic brain tumors. Cell 37: 367-379.

Buchman, A.R., L. Burnett, and P. Berg. 1981. The SV40 nucleotide sequence. In Molecular biology of tumor viruses 2nd ed., revised (ed. J. Tooze), pp. 799-841. Cold Spring Harbor Laboratory, Cold Spring Harbor, New York.

Caterina, J.J., T.M. Ryan, K.M. Pawlik, R.D. Palmiter, R.L. Brinster, R.R. Behringer, and T.M. Townes. 1991. Human $\beta$-globin locus control region: Analysis of the 5' DNaseI hypersensitive site HS2 in transgenic mice. Proc. Natl. Acad. Sci. 88: 1626-1630.

Chamberlin, M.J. and T. Ryan. 1982. Bacteriophage DNA-dependent RNA polymerases. In The enzymes (ed. P. Boyer), vol. 15, pp. 87-108. Academic Press, New York.

Chen, W., S. Tabor, and K. Struhl. 1987. Distinguishing between mechanisms of eukaryotic transcriptional activation with bacteriophage T7 RNA polymerase. Cell 50: 1047-1055.

Clark, D.J. and G. Felsenfeld. 1992. A nucleosome core is transferred out of the path of a transcribing polymerase. Cell 71: 11-22.

Clark-Adams, C.D., D. Norris, M.A. Osley, J.S. Fassler, and F. Winston. 1988. Changes in histone gene dosage alter transcription in yeast. Genes \& Dev. 2: 150-159.

Cockerill, P.N., M.-H. Yuen, and W.T. Garrard. 1987. The enhancer of the immunoglobulin heavy chain locus is flanked by presumptive chromosomal loop anchorage elements. $I$. Biol. Chem. 262: 5394-5397.

Durrin, L.K., R.K. Mann, P.S. Kayne, and M. Grunstein. 1991. Yeast histone $\mathrm{H} 4 \mathrm{~N}$-terminal sequence is required for promoter activation in vivo. Cell 65: 1023-1031.

Elgin, S.C.R. 1988. The formation and function of DNaseI hypersensitive sites in the process of gene activation. $/$. Biol. Chem, 263: 19259-19262.

Ephrussi, A., G.M. Church, S. Tonegawa, and W. Gilbert. 1985. B lineage-specific interactions of an immunogobulin enhancer with cellular factors in vivo. Science 227: 134-140.

Felsenfeld, G. 1992. Chromatin as an essential part of the transcriptional mechanism. Nature 355: 219-224.

Ferrier, P., B. Krippl, T.K. Blackwell, A. Furley, H. Suh, A. Winoto, W.D. Cook, L. Hood, F. Constantini, and F.W. Alt. 1990. Separate elments control DJ and VDJ rearrangement in a transgenic recombination substrate. EMBO /. 9: 117-125.

Ford, A.M., C.A. Bennet, L.E. Healy, E. Navarro, E. Spooncer, and M.F. Greaves. 1992. Immunoglobulin heavy-chain and CD3 $\delta$-chain gene enhancers are DNasel hypersensitive in hemopoietic progenitor cells. Proc. Natl. Acad. Sci. 89: 3423-3428.

Forrester, W.C., S. Takegama, T. Papayannopoulou, G. Stamatoyannopoulos, and M. Groudine. 1987. Evidence for a locus activation region: The formation of developmentally stable hypersensitive sites in globin-expressing hybrids. Nucleic Acids Res. 15: 10159-10177.

Forrester, W.C., E. Epner, M.C. Driscoll, T. Enver, M. Brice, T. Papayannopoulou, and M. Groudine. 1990. A deletion of the human $\beta$-globin locus activation region causes a major alteration in chromatin structure and replication across the entire $\beta$-globin locus. Genes \& Dev. 4: 1637-1649. 
Gasser, S.M. and U.K. Laemmli. 1986. Cohabitation of scaffoldbinding regions with upstream/enhancer elements of three developmentally regulated genes of D. melanogaster. Cell 46: $521-530$.

Gerster, T., P. Matthias, M. Thali, J. Jiricny, and W. Schaffner. 1987. Cell type-specificity elements of the immunoglobulin heavy chain gene enhancer. $E M B O ~ J .6:$ 1323-1330.

Gillies, S.D., S.L. Morrison, V.T. Oi, and S. Tonegawa. 1983. A tissue-specific transcription enhancer element is located in the major intron of a rearranged immunoglobulin heavy chain gene. Cell 33: 717-728.

Greaves, D.R., F.D. Wilson, G. Lang, and D. Kioussis. 1989. Human CD2 3'-flanking sequences confer high-level, T-cellspecific, position-independent gene expression in transgenic mice. Cell 56: 979-986.

Gross, D.S. and W.T. Garrard. 1988. Nuclease hypersensitive sites in chromatin. Annu. Rev. Biochem. 57: 159-197.

Grosschedl, R. and D. Baltimore. 1985. Cell-type specificity of immunoglobulin gene expression is regulated by at least three DNA sequence elements. Cell 41: 885-897.

Grosschedl, R. and M. Marx. 1988. Stable propagation of the active transcriptional state of an immunoglobulin gene requires continuous enhancer function. Cell 55: 645-654.

Grosveld, F., G. Blom van Assendelft, D.R. Greaves, and G. Kollias. 1987. Position-independent, high-level expression of the human $\beta$-globin gene in transgenic mice. Cell 51: 975985.

Han, S. and M. Grunstein. 1988. Nucleosome loss activates downstream promoters in vivo. Cell 55: 1137-1145.

Hirschhorn, S.A., S.A. Brown, C.D. Clark, and F. Winston. 1992. Evidence that SNF2/SWI2 and SNF5 activate transcription in yeast by altering chromatin structure. Genes \& Dev. 6: $2288-2298$.

Jarman, A.P. and D.R. Higgs. 1988. Nuclear scaffold attachment sites in the human globin gene complexes. EMBO I. 7: 33373344.

Jenuwein, T. and R. Grosschedl. 1991. Complex pattern of immunoglobulin $\mu$ gene expression in normal and transgenic mice: Nonoverlapping regulatory sequences govern distinct tissue specificities. Genes \& Dev. 5: 932-943.

Käs, E., L. Poljak, Y. Adachi, and U.K. Laemmli. 1993. A model for chromatin opening: Stimulation of topoisomerase II and restriction enzyme cleavage of chromatin by distamycin. $E M B O$ \%. 12: 115-126.

Kellum, R. and P. Schedl. 1991. A position-effect assay for boundaries of higher order chromosomal domains. Cell 64: 941-950.

Kimura, A., A. Israël, O. Le Bail, and P. Kourilsky. 1986. Detailed analysis of the mouse $\mathrm{H}-2 \mathrm{~K}^{\mathrm{b}}$ promoter: Enhancer-like sequences and their role in the regulation of class I gene expression. Cell 44: 261-272.

Knezetic, J.A., G.A. Jacob, and D.S. Luse. 1988. Assembly of RNA polymerase II preinitiation complexes before assembly of nucleosomes allows efficient initiation of transcription on nucleosomal templates. Mol. Cell. Biol. 8: 3114-3121.

Kornberg, R.D. and Y. Lorch. 1991. Irresistible force meets immovable object: Transcription and the nucleosome. Cell 67: 833-836.

Laybourn, P.J. and J.T. Kadonaga. 1991. Role of nucleosomal cores and histone $\mathrm{H} 1$ in regulation of transcription by RNA polymerase II. Science 254: 238-245.

Leavitt, J., P. Gunning, P. Porreca, S. Ng, C. Lin, and L. Kedes. 1984. Molecular cloning and characterization of mutant and wild-type human $\beta$-actin genes. Mol. Cell. Biol. 4: 19611969.

Lee, M.-S and W.T. Garrard. 1992. Uncoupling gene activity from chromatin structure: Promoter mutations can inactivate transcription of the yeast HSP82 gene without eliminating nucleosome-free regions. Proc. Natl. Acad. Sci. 89: 9166-9170.

Lenardo, M., J.W. Pierce, and D. Baltimore. 1987. Protein binding sites in immunoglobulin gene enhancers determine transcriptional activity and inducibility. Science 236: 15731577.

Lennon, G.G. and R.P. Perry. 1985. C $\mu$-containing transcripts initiate heterogeneously within the $\mathrm{IgH}$ enhancer region and contain a novel 5'-nontranslatable exon. Nature 318: 475478.

Libermann, T.A. and D. Baltimore. 1991. Transcriptional regulation of immunoglobulin gene expression. Mol. Aspects Cell. Regul. 6: 385-407.

Lue, N.F., A.R. Buchman, and R.D. Kornberg. 1989. Activation of yeast RNA polymerase II transcription by a thymidinerich upstream element in vitro. Proc. Natl. Acad. Sci. 86: $486-490$.

Maniatis, T., S. Goodbourn, and J.F. Fischer. 1987. Regulation of inducible and tissue-specific gene expression. Science 236: 1237-1245.

McKnight, R.A., A. Shamay, L. Sankaran, R.J. Wall, and L. Hennighausen. 1992. Matrix-attachment regions can impart position-independent regulation of a tissue-specific gene in transgenic mice. Proc. Natl. Acad. Sci. 89: 6943-6947.

Nelsen, B., G. Tian, B. Erman, J. Gregoire, R. Maki, B. Graves, and R. Sen. 1993. Regulation of lymphoid-specific immunoglobulin $\mu$ heavy chain gene enhancer by ets-domain proteins. Science 261: 82-86.

Ondek, B., A. Shepard, and W. Herr. 1988. Discrete elements within the SV40 enhancer region display different cell-specific enhancer activities. EMBO I. 6: 1017-1025.

O'Neill, T.E., M. Roberge, and E.M. Bradbury. 1992. Nucleosome arrays inhibit both initiation and elongation of transcripts by bacteriophage T7 RNA Polymerase. $/$. Mol. Biol. 223: 67-78.

Philipsen, S., S. Pruzina, and F. Grosveld. 1993. The minimal requirements for activity in transgenic mice of hypersensitive site 3 of the $\beta$ globin locus control region. EMBO $J$. 12: $1077-1085$.

Pikaart, M., J. Feng, and B. Villeponteau. 1992. The polyomavirus enhancer activates chromatin accessibility on integration into the HPRT gene. Mol. Cell. Biol. 12: 5785-5792.

Piña, B., Y. Brüggemeier, and M. Beato. 1990. Nucleosome positioning modulates accessibility of regulatory proteins to the mouse mammary tumor virus promoter. Cell 60: 719731.

Pfeifer, G.P. and A.D. Riggs. 1991. Chromatin differences between active and inactive $\mathrm{X}$ chromosomes revealed by genomic footprinting of permeabilized cells using DNase I and ligation-mediated PCR. Genes \& Dev. 5: 1102-1113.

Ptashne, M. 1986. Gene regulation by proteins acting nearby and at a distance. Nature 322: 697-701.

Reik, A., G. Schütz, and A.F. Stewart. 1991. Glucocorticoids are required for establishment and maintainance of an alteration in chromatin structure: Induction leads to a reversible disruption of nucleosomes over an enhancer. $E M B O ~ I .10$ : 2569-2576.

Reitman, M., E. Lee, H. Westphal, and G. Felsenfeld. 1993. An enhancer/locus control region is not sufficient to open chromatin. Mol. Cell. Biol. 13: 3990-3998.

Rosenberg, N. and D. Baltimore. 1976. A quantitative assay for transformation of bone marrow cells by Abelson murine leukemia virus. J. Exp. Med. 143: 1453-1463.

Ruezinsky, D., H. Beckmann, and T. Kadesch. 1991. Modula- 
tion of the IgH enhancer's cell type specificity through a genetic switch. Genes \& Dev. 5: 29-37.

Sambrook, J., E.F. Fritsch, and T. Maniatis. 1989. Molecular cloning: A laboratory manual, 2nd edition. Cold Spring Harbor Laboratory Press, Cold Spring Harbor, New York.

Saragosti, S., G. Moyne, and M. Yaniv. 1980. Absence of nucleosomes in a fraction of SV40 chromatin between the origin of replication and the region coding for the late leader RNA. Cell 20: 65-73.

Scheuermann, R.H. and U. Chen. 1989. A developmental-specific factor binds to suppressor sites flanking the immunoglobulin heavy-chain enhancer. Genes \& Dev. 3: 1255-1266.

Schirm, S., J. Jiricny, and W. Schaffner. 1987. The SV40 enhancer can be dissected into multiple segments, each with a different cell type specificity. Genes \& Dev. 1: 65-74.

Schlissel, M., A. Voronova, and D. Baltimore. 1991. Helix-loophelix transcription factor E47 activates germ-line immunoglobulin heavy chain gene transcription and rearrangement in a pre-T cell line. Genes \& Dev. 5: 1367-1376.

Serfling, E., M. Jasin, and W. Schaffner. 1985. Enhancers and eukaryotic gene transcription. Trends Genet. 1: 224-230.

Stief, A., D.M. Winter, W.H. Strätling, and A.E. Sippel. 1989. A nuclear DNA attachment element mediates elevated and position-independent gene activity. Nature 341: 343-345.

$\mathrm{Su}, \mathrm{L} . \mathrm{K}$. and T. Kadesch. 1990. The immunoglobulin heavychain enhancer functions as the promoter for I $\mu$ sterile transcription. Mol. Cell. Biol. 10: 2619-2624.

Svaren, J. and R. Chalkley. 1990. The structure and assembly of active chromatin. Trends Genet. 6: 52-56.

Talbot, D., S. Philipsen, P. Fraser, and F. Grosveld. 1990. Detailed analysis of the site 3 region of the human $\beta$-globin dominant control region. EMBO J. 9: 2169-2177.

Taylor, I.C.A., J.L. Workman, T.J. Schuetz, and R.E. Kingston. 1991. Facilitated binding of GAL4 and heat shock factor to nucleosomal templates: Differential function of DNA-binding domains. Genes \& Dev. 5: 1285-1298.

Townes, T.M. and R.R. Behringer. 1990. Human globin locus activation region (LAR): Role in temporal control. Trends Genet. 6: 219-223.

Travers, A.A. 1992. The reprogramming of transcriptional competence. Cell 69: 573-575.

Varshavsky, A.J., O. Sundin, and M. Bohn. 1979. A stretch of "late" SV40 viral DNA about 400bp long which induces the origin of replication is specifically exposed in SV40 minichromosomes. Cell 16: 453-466.

Weintraub, H. 1985. Assembly and propagation of repressed and derepressed chromosomal states. Cell 42: 705-711.

Weintraub, H. and M. Groudine. 1976. Chromosomal subunits in active genes have an altered conformation. Science 193: 848-856.

Williamson, P. and G. Felsenfeld. 1978. Transcription of histone-covered T7 DNA by Escherichia coli RNA polymerase. Biochemistry 17: 5695-5705.

Wilson, C., H.J. Bellen, and W.J. Gehring. 1990. Position effects on eukaryotic gene expression. Annu. Rev. Cell Biol. 6: 679714.

Wolffe, A.P. 1992. Chromatin: Structure and function, pp. 151155. Academic Press, London.

Workman, J.L. and R.E. Kingston. 1992. Nucleosome displacement in vitro via a metastable transcription factor-nucleosome complex. Science 258: 1780-1784.

Workman, J.L., S.M. Abmayr, W.A. Cromlish, and R.G. Roeder. 1988. Transcriptional regulation by the immediate early protein of pseudorabies virus during in vitro nucleosome assembly. Cell 55: 211-219.

Wu, C., Y.-C. Wong, and S.C.R. Elgin. 1979. The chromatin structure of specific genes: II. Disruption of chromatin structure during gene activity. Cell 16: 807-814.

Zenke, M., T. Grundström, H. Matthes, M. Wintzereith, C. Schatz, A. Wildeman, and P. Chambon. 1986. Multiple sequence motifs are involved in SV40 enhancer function. EMBO I. 5: 378-397.

Zhao, K., E. Käs, E. Gonzales, and U.K. Laemmli. 1993. SARdependent mobilization of histone $\mathrm{H} 1$ by $\mathrm{HMG}-\mathrm{I} / \mathrm{Y}$ in vitro: HMG-I/Y is enriched in H1-depleted chromatin. EMBO $I$. 12: 3237-3247. 


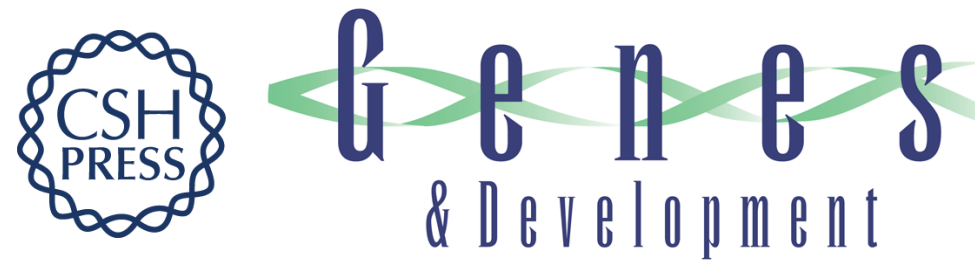

\section{The immunoglobulin mu enhancer core establishes local factor access in nuclear chromatin independent of transcriptional stimulation.}

T Jenuwein, W C Forrester, R G Qiu, et al.

Genes Dev. 1993, 7:

Access the most recent version at doi:10.1101/gad.7.10.2016

References This article cites 84 articles, 31 of which can be accessed free at:

http://genesdev.cshlp.org/content/7/10/2016.full.html\#ref-list-1

License

Email Alerting

Service

Receive free email alerts when new articles cite this article - sign up in the box at the top right corner of the article or click here.

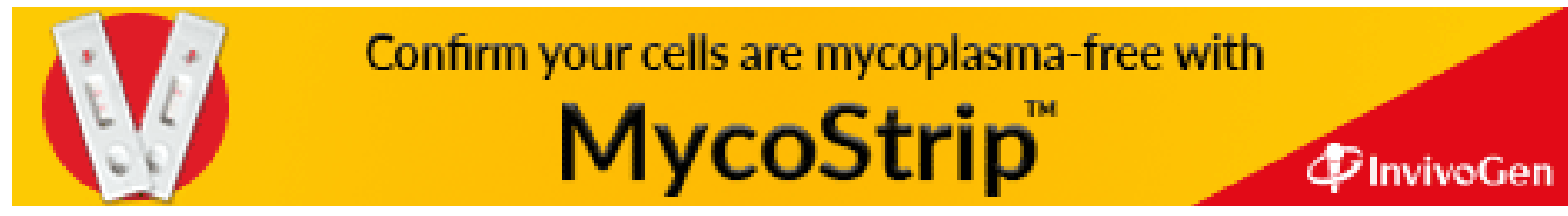

